OPEN ACCESS

Edited by:

Vito Longo,

Istituto Nazionale dei Tumor (IRCCS), Italy

Reviewed by:

John D. Martin,

Independent Researcher,

Tokyo, Japan

Lucas Treps,

VIB KU Leuven Center for Cancer Biology, Belgium

${ }^{*}$ Correspondence:

Niels Heemskerk n.heemskerk@amsterdamumc.n

Specialty section:

This article was submitted to

Cancer Immunity and Immunotherapy,

a section of the journal

Frontiers in Immunology

Received: 17 July 2020 Accepted: 19 October 2020 Published: 11 November 2020

Citation:

Duru $G$, van Egmond $M$ and Heemskerk N (2020) A Window of

Opportunity: Targeting

Cancer Endothelium to

Enhance Immunotherapy.

Front. Immunol. 11:584723. doi: 10.3389/fimmu.2020.584723

\section{A Window of Opportunity: Targeting Cancer Endothelium to Enhance Immunotherapy}

\author{
Gizem Duru $^{1}$, Marjolein van Egmond ${ }^{1,2}$ and Niels Heemskerk ${ }^{1 *}$ \\ ${ }_{1}^{1}$ Amsterdam UMC, Vrije Universiteit Amsterdam, Department of Molecular Cell Biology and Immunology, Cancer Center \\ Amsterdam, Amsterdam Infection \& Immunity, Amsterdam, Netherlands, ${ }^{2}$ Amsterdam UMC, Vrije Universiteit Amsterdam, \\ Department of Surgery, Cancer Center Amsterdam, Amsterdam, Netherlands
}

Vascular abnormalities in tumors have a major impact on the immune microenvironment in tumors. The consequences of abnormal vasculature include increased hypoxia, acidosis, high intra-tumoral fluid pressure, and angiogenesis. This introduces an immunosuppressive microenvironment that alters immune cell maturation, activation, and trafficking, which supports tumor immune evasion and dissemination of tumor cells. Increasing data suggests that cancer endothelium is a major barrier for traveling leukocytes, ranging from a partial blockade resulting in a selective endothelial barrier, to a complete immune infiltration blockade associated with immune exclusion and immune desert cancer phenotypes. Failed immune cell trafficking as well as immunosuppression within the tumor microenvironment limits the efficacy of immunotherapeutic approaches. As such, targeting proteins with key roles in angiogenesis may potentially reduce immunosuppression and might restore infiltration of anti-tumor immune cells, creating a therapeutic window for successful immunotherapy. In this review, we provide a comprehensive overview of established as well as more controversial endothelial pathways that govern selective immune cell trafficking across cancer endothelium. Additionally, we discuss recent insights and strategies that target tumor vasculature in order to increase infiltration of cytotoxic immune cells during the therapeutic window of vascular normalization hereby improving the efficacy of immunotherapy.

Keywords: tumor angiogenesis, cancer endothelium, immune cell trafficking, vascular normalization, immunotherapy

\section{INTRODUCTION}

Immunotherapy of cancer boost the host immune system to eradicate transformed cancerous cells. In the last decade a great variety of immunotherapeutic approaches emerged that transformed modern cancer treatment, including antibodies targeting immune inhibitory checkpoints (e.g., PD-1 and CTLA-4), monoclonal antibodies (mAbs) directed against tumor-associated antigens (TAA), anticancer vaccines, and chimeric antigen receptor $\mathrm{T}$ cells (CAR $\mathrm{T}$ cells). Novel immunotherapeutic approaches have expanded current treatment options tremendously, in particular for patients that have unresectable or metastatic solid tumors. Checkpoint blockade with PD-1 and CTLA-4 showed durable control of highly aggressive melanomas and has led to spectacular results showing rapid eradication of large metastatic tumors in response to one dose of Ipilimumab (CTLA-4) and 
Nivolumab (PD-1) (1, 2). As such, immunotherapy was acknowledged as breakthrough of the year 2017 by the journal Science and currently accepted as treatment option for many metastatic solid tumors including metastatic melanoma as well as lung cancer. However, immunotherapy does not help everyone. Approximately $50 \%-80 \%$ of patients that receive immunotherapy do not benefit from the treatment, and many patients experience severe side effects (3). Up to now multiple mechanisms have been described that can induce resistance to immunotherapy, underscoring the complexity and heterogeneity in immunotherapeutic responses between individuals.

Classifying tumors according their immunological status and localization of immune cells within the tumor supports the existence of three different cancer-immune phenotypes (4-6). Firstly, the immune inflamed phenotype is characterized by high infiltration of immune cells in the tumor. Secondly, the immuneexcluded phenotype is characterized by the restriction of immune cells at the periphery of cancer nests $(5,6)$, or by confinement of immune cells in stromal regions of the tumor (7), which can also be present further towards the centre of the tumor $(6,8)$. Immune-excluded tumors may reflect the presence of inhibitory vascular growth factors (9), vascular barriers (10), inhibitory receptors on endothelium (11), might be induced by a specific chemokine state (12) or inhibition in stromal regions ( 7 , 13). Lastly, the immune desert phenotype is characterized by limited neoantigens, tolerance induction and lack of appropriate $\mathrm{T}$ cell priming or activation (4-6), resulting in the absence of immune cells. While clinical responses to immunotherapy occur most often in patients with inflamed tumors, clinical responses in immune-excluded tumors are uncommon and not observed in tumors exhibiting the immune-desert phenotype $(4,14)$. Each immune phenotype is associated with specific underlying mechanisms that might limit immunotherapeutic responses. For instance, in immune deserts, a lack of sufficient neoantigens to activate cytotoxic $\mathrm{T}$ cells has been proposed while in inflamed tumors $\mathrm{T}$ cell exhaustion might be a major factor contributing to therapeutic insensitivity.

As an alternative explanation for the therapeutic variety in response rates to immunotherapy, we support the hypothesis that abnormal tumor vasculature fulfills a central position in selective immune cell trafficking, which in part regulatesthe localization of immune cells within the tumor site, reflecting the various immune phenotypes. In addition, abnormal tumor vasculature may have a key role in maintenance of immunosuppression in tumors, limiting immunotherapeutic responses (15-18). Dysfunctional tumor vessels give rise to hypoxia that in turn lowers $\mathrm{pH}$, creates leaky vasculature, and impairs fluid drainage increasing interstitial fluid pressure, which altogether supports an unfavorable tumor microenvironment (TME) and cancer metastasis (19). These circumstances in tumors alter the functionality of many immune effector cells, leading to the release of immunosuppressive cytokines that disables immune effector functions rendering immunotherapy ineffective (20-24).

Equally important, angiogenic factors released in response to hypoxia interfere with immune cell trafficking (10, 11, 13, 25-29).
The severity of impaired leukocyte entry into tumors ranges from a partial blockade resulting in a selective endothelial barrier in case of inflamed and in part in immune excluded tumors, to a complete immune infiltration blockade associated with tumors lacking immune infiltration. Several studies showed that the efficacy of immunotherapy was strongly related to tumor infiltrating leukocyte levels (30-34). The existence of noninflamed tumors supports the idea that exclusion of immune cells from the TME plays an important role in cancer escape and resistance to immunotherapy.

Several lines of evidence have shown that vascular normalization using anti-angiogenesis agents could restore leukocyte recruitment (31-34) into the tumor microenvironment and relieve immunosuppression $(32,35,36)$. Targeting dysfunctional tumor vasculature using antiangiogenic agents has therefore the potential to create a window of therapeutic opportunity in which immunotherapy could have a better outcome then used as a single therapeutic agent $(15,17,37)$.

\section{HOW ABNORMAL TUMOR VASCULATURE CONTRIBUTES TO IMMUNOSUPPRESSION IN CANCER}

Early stage tumors are going through many cycles of growth and death. As nutrients and oxygen cannot reach cells in the tumor's core, proliferation is followed by necrosis confining the size of the primary tumor to about 2-3 square millimeters (38). A tumor remains in this state until it acquires the ability to control its own growth through induction of angiogenesis. This event is called the angiogenic switch (39), which supports tumor progression in various ways. It improves supply of nutrients and oxygen and contributes to removal of toxic waste products (40). In addition, the connection to the vascular network facilitates infiltration of inflammatory immune cells into the tumor, increasing the complexity of the tumor microenvironment. Hypoxia as well as acquired mutations in proangiogenic growth factor pathways (e.g., loss of PTEN) have been implicated as key factors driving tumors into the angiogenic switch $(17,41-43)$.

In the 1980 's, it was proposed that tumors behave as a wounds that do not heal (44). There are many similarities between developing tumors and healing wounds, sharing overlapping biological players and pathways including recruitment of leukocytes and angiogenesis (45). Physiological angiogenesis in wounds typically occurs through vessel destabilization, sprouting, endothelial migration and proliferation, followed by resolution and stabilization of the new vessel. In cancer, angiogenesis is, however, characterized by a failure of the resolution phase. This results in a highly abnormal and disorganized vascular network that contains many intercellular gaps, abnormal spouts, and holds significant areas which are not well perfused (Figure 1). Intravital imaging in human melanoma tumors revealed that up to half of the neovasculature in tumors does not support blood flow (46). The lack of vessel perfusion creates areas of hypoxic tumor tissue that in turn may reinforce angiogenesis, initiating a vicious cycle, 


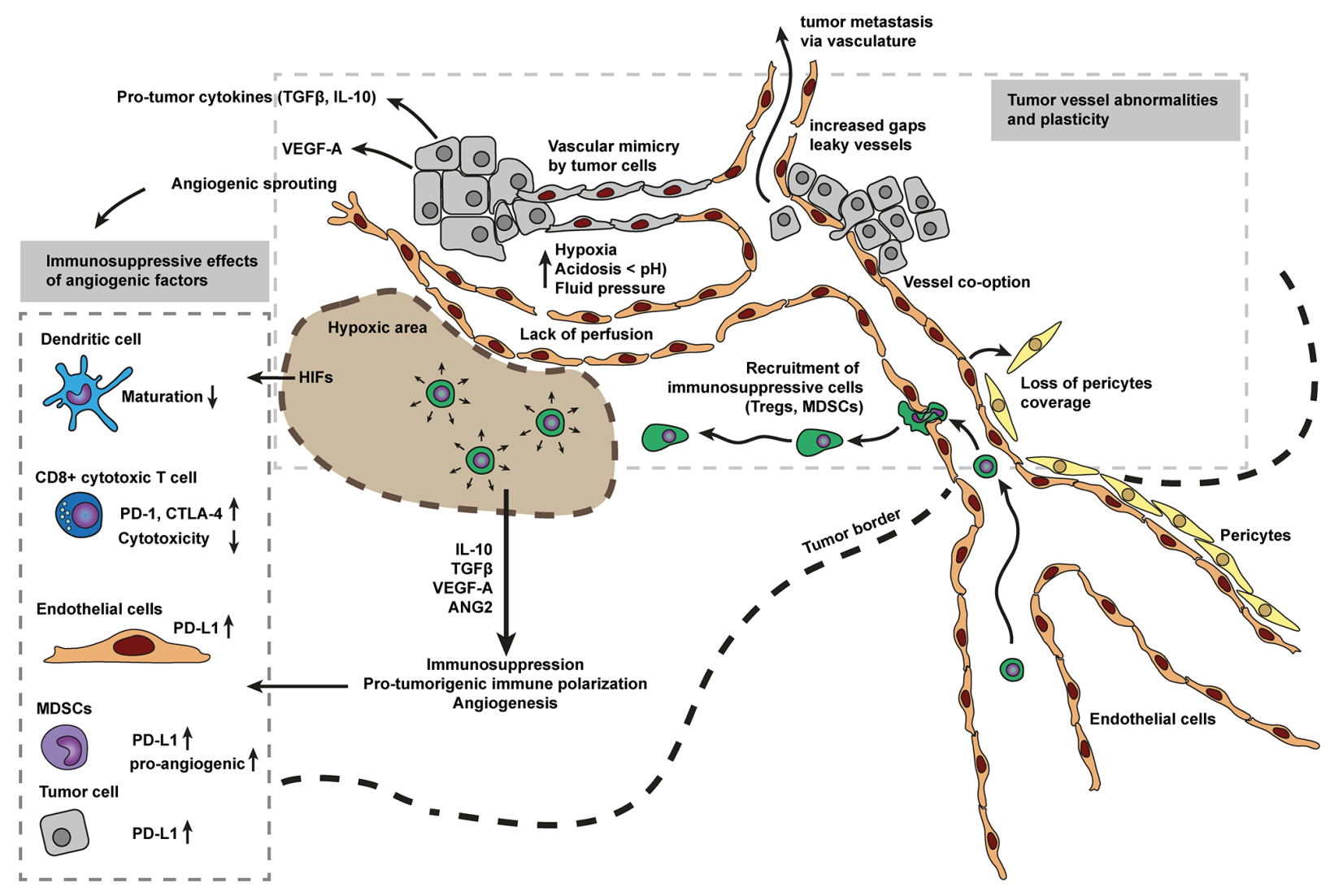

FIGURE 1 | Tumor vessel abnormalities and angiogenesis as main driver for immunosuppression. The disorganized vascular network in tumors contains many intercellular gaps, abnormal sprouts, and holds significant areas which are not well perfused. The lack of vessel perfusion creates areas of hypoxic tumor tissue that in turn may reinforce angiogenesis, initiating a vicious cycle, as hypoxia is a key inducer of angiogenesis. Hypoxic zones in tumors also attract myeloid derived suppressor cells (MDSCs), tumor associated macrophages (TAMs) and regulatory T cells (Treg cells). Which in turn, respond to hypoxia by secreting various antiinflammatory cytokines and growth factors (e.g., IL10, TGF $\beta$, VEGF, and ANG2). These cytokines and growth factors have profound immunosuppressive effects on immune cells including pro-tumorigenic immune cell polarization, inhibition of cell maturation, inhibit cytotoxic capacity, increase expression of immune inhibitory checkpoints (e.g., PD-1, CTLA-4) and alter leukocyte recruitment. Tumor vessels are not well matured, characterized by low pericyte coverage. Low pericyte coverage causes improper and loose endothelial cell-cell contacts and allows tumor cells to metastasize via the bloodstream. Cancer endothelium is considered to be a heterogeneous population of cells, derived from vessel co-option, sprouting, bone-marrow, and/or vessel wall endothelial progenitor cells, transdifferentiated myeloid, and mesenchymal cells, or surprisingly derived from tumor cells mimicking endothelial cells.

as hypoxia is a key inducer of angiogenesis (19). In cells, low oxygen levels are sensed by special proteins called hypoxiainducible factors (HIFs) that in response to hypoxia translocate to the nucleus to initiate transcription of genes to promote cell survival in hypoxic conditions. These include glycolysis enzymes, which allow ATP synthesis in an oxygen-independent manner and pro-angiogenic proteins such as vascular endothelial growth factor (VEGF) and angiopoietin-2 (Ang2) (47).

In addition to induction of angiogenesis, pro-angiogenic proteins such as VEGF can also induce immunosuppressive functions (15) (Figure 1). One of the first described immunosuppressive mechanisms of VEGF was the inhibition of dendritic cell maturation with major consequences for presentation of tumor associated antigens (48). In addition, VEGF has also been implicated in inhibition of T cell function by inducing increased expression of immune inhibitory checkpoints including PD-1, CTLA-4, and Tim-3 mediating T cell exhaustion and anergy $(9,49)$. An additional factor found in the hypoxic tumor microenvironment are increased levels of HIFs (50). HIFs promote expression of ligands for immune inhibitory checkpoints (Figure 1). For instance, HIF1 $\alpha$ increases the expression of PD-L1 on myeloid derived suppressor cells (MDSCs), tumor cells, DCs, and macrophages, hereby limiting $\mathrm{T}$ cell activation (20).

Hypoxic zones in tumors also attract $\operatorname{MDSCs}(21,51,52)$, tumor associated macrophages (TAMs) $(22,53)$ and regulatory T cells (Treg cells) $(23,54)$. In turn, these immune subtypes respond to hypoxia by secreting various anti-inflammatory cytokines and growth factors (e.g., IL10, TGF $\beta$, VEGF and ANG2) in an attempt to relieve hypoxic stress (Figure 1). Many of these factors, however, contribute to immunosuppression and cancer escape through pro-tumorigenic immune cell polarization (24) or partial leukocyte trafficking blockade. Low hypoxia levels have also been reported to slow down tumor infiltrating lymphocytes (55). Collectively, this data shows how abnormal tumor vasculature contributes to immunosuppression in cancer. 


\section{CONSEQUENCES OF ANGIOGENESIS IN TUMORS FOR LEUKOCYTE TRAFFICKING}

The vascular network provides a conduit for leukocytes to reach specific places in the body. The endothelium, paving the inner lining of the vascular network, acts as a gatekeeper for leukocytes, providing guidance where to exit the bloodstream. Leukocytes breaching the endothelium, also referred to as leukocyte transendothelial migration or diapedesis, is a common process that occurs during physiological as well as pathological conditions (56). For instance, immune cells travel in and out of lymphoid structures via high endothelial venules to perform immune surveillance or breach endothelial barriers to counter a bacterial infection. During acute inflammation, pro-inflammatory cytokines induce endothelial cell activation, creating local endothelial patches that express high levels of cell adhesion molecules (CAMs, i.e., Selectins, ICAM-1 and VCAM-1) at their surface to mark the exit site for leukocytes, close to the inflammatory site (57). This active endothelial state allows leukocytes to cross the endothelial barrier.

In general, every leukocyte diapedesis event occurs through the same fundamentally conserved multistep process, which was first described by Springer and Butcher et al, as a three step process, that became known as the multistep paradigm of leukocyte transendothelial migration $(58,59)$. The current steps include rolling, crawling, firm adhesion, arrest, docking structure formation, and transendothelial migration $(56,60)$.

Selectin-mediated interactions promote leukocyte recruitment to the site of inflammation or cancer progression (61). Endothelialselectins, including E-selectin (also known as CD62-E, ELAM-1) and P-selectin (CD62-P) mediate the first step in the multistep process of leukocyte diapedesis (61). The primary selectin ligand on leukocytes, P-selectin glycoprotein ligand-1 (PSGL-1) triggers intracellular signaling through $\mathrm{P}$-selectin or E-selectin binding mediating tethering and rolling of various hematopoietic cells $(61,62)$. Secondly, selective chemokines presented on the endothelial surface by heparan sulfate activate specific integrin subsets expressed by leukocytes (e.g., LFA-1 and VLA-4), and result in more stable leukocyte adhesion via CAM binding on the endothelium. Leukocyte binding to endothelial CAMs (e.g., ICAM1 and VCAM-1) support the adhesion phase including crawling, firm adhesion, arrest and docking structure formation $(63,64)$. The last step, transmigration, occurs either between two or more adjacent endothelial cells (paracellular route) or through the cell body of an individual endothelial cell (transcellular route). In both cases, an Factin ring within the endothelium prevents vascular rupture and leakage while leukocytes pass the endothelial cell layer (57).

In addition, several processes shape the multistep paradigm and may refine leukocyte trafficking at predefined endothelial "hotspots" (60). These include the recruitment of leukocytes towards an optimal concentration of chemokines (chemotaxis), the density of adhesion molecules (haptotaxis), cellular stiffness (durotaxis) and migrating of leukocytes along the path of least resistance (tenertaxis), which also governs decisions making where to exit the endothelium $(65,66)$.

To infiltrate a tumor and to become part of the TME, immune cells must adhere and breach the endothelial lining of cancer vessels.
The vasculature in cancer is, however, not normal. On a genetic level tumor endothelium differs from those located in normal resting tissues. Cytogenetic studies on epithelial renal cell carcinoma and nonepithelial (liposarcoma and melanoma) tumors have reported chromosomal aberrations and aneuploidy in tumor endothelial cells $(67,68)$, indicating that tumor endothelial cells, like tumor cells, can be genetically instable (67). On the transcription level, two particularly interesting studies compared the gene expression profiles of endothelial cells isolated from five distinct tumors and eight resting normal tissues $(69,70)$. Of the transcripts identified, 25 were overexpressed in tumor versus normal endothelium. Most of the genes identified had expected roles in angiogenesis and cellcycle control, but those specific to tumor endothelium were mainly cell surface molecules of unknown function. Another intriguing study revealed that the most downregulated gene classes in tumor endothelial cells involved antigen presentation (i.e., Major histocompatibility complex class I, II), immune cell homing molecules (i.e., ICAM-1), and chemotaxis related molecules (i.e., CCL2, CCL18, and IL6), which might explain how tumor cells gain immuno-tolerance (71). Furthermore, single-RNA sequencing revealed the breadth in heterogeneity of lung tumor endothelial cell phenotypes in human patients and mouse tumor model systems. Tip tumor endothelial cells were congruent across species and models and shared conserved markers (72).

On a cellular level the origin of cancer endothelium considers various cellular sources (Figure 1). Endothelial patches are homogeneous, and can be derived from angiogenesis-induced spouts, co-opt nearby vessels, or are derived from bone-marrow or vessel wall endothelial progenitor cells $(73,74)$. Additionally, vessels may also be derived from unexpected sources, including endothelial cells derived from transdifferentiated myeloid and mesenchymal cells, or even from tumor cells mimicking endothelial cells (74). The multi-source origin of endothelial cells in abnormal tumor vessels may explain the plasticity of tumor vessels to escape anti-angiogenesis therapy (74).

Gene expression profiles in cancer endothelial cells might also depend on tumor size. For instance, it was suggested that smaller tumors express different angiogenic gene profiles compared to larger tumors. One study that explored this relationship found that genes associated with angiogenesis did not change during the different growth stages. However, cell surface molecules involved in leukocyte trafficking, i.e., ICAM-1 and VCAM-1 were downregulated in intermediate and large tumors (75). Moreover, several papers have shown a clear link between angiogenesismodulatory molecules such as VEGF and basic fibroblast growth factor (bFGF) and downregulation of CAMs on tumor endothelial cells $(76,77)$. Together this data shows how angiogenesis modulating factors interfere with CAM expression on tumor endothelium which alters leukocyte infiltration into tumors.

\section{CANCER ENDOTHELIUM A SELECTIVE BARRIER FOR LEUKOCYTES}

As evidenced by the various immune phenotypes in cancer, i.e., desert, immune-excluded and inflamed tumors the severity of 
impaired leukocyte entry into tumors ranges from a partial blockade to a complete immune infiltration blockade into tumors. The fact that some immunosuppressive immune cells such as regulatory $\mathrm{T}$ cells (Tregs) and MDSCs can enter the TME while cytotoxic effector cells are excluded also suggests a selective barrier at the level of the endothelium. What factors contribute to this selectivity is currently debated and of ongoing investigation.

Selective immune cell trafficking is regulated by a unique combination of endothelial specific CAMs and surface bound chemokines that interact with matching counterparts (integrins and chemokine receptors) expressed by specific leukocyte subtypes. In the context of cancer there are multiple pathways and mechanisms described that drive selective immune cell trafficking. It is important to realize that some of these pathways exist only temporally as they are continuously subjected to changing microenvironments as tumor development progresses and pathways might differ across tumor and tissue type. For many tumor types there is limited information on this topic so the represented information is based on a selected number of studies and may therefore not cover all tumor microenvironments and tumor types. Models (Figures 2-7) are simplified to improve understandability and serve as a starting point to understand and unravel the complete breadth of molecules involved in selective immune cell trafficking of diverse immune subtypes across diverse tumor types and tissues. While many parallels between inflammation and cancer development have been described, it remains to be evaluated how the various selectins, CAMs and chemokines mediate selective trafficking in cancer. We will now discuss the most established mechanisms of selective immune cell trafficking in cancer.

\section{CD8 T Cell Trafficking Across Cancer Endothelium}

In non-lymphoid tissues, resting endothelial cells lining small capillaries are usually refractory to leukocyte adhesion. Tissue entry via the vasculature occurs only occasionally by monocytes and a few recirculating $\mathrm{T}$ lymphocytes. L-selectin controls the capacity for naïve $\mathrm{T}$ cells to migrate to the lymph nodes, whereas $\mathrm{P}$ - and E-selectin capture activated T cells on activated inflamed endothelium to initiate their migration into non-lymphoid tissues (62). In tumors, initiation of $\mathrm{T}$ cell infiltration has been suggested to start with an initial infiltration of a few $\mathrm{T}$ cells, followed by a large influx of both specific and nonspecific $\mathrm{T}$ cells (78).

To enter tumor tissue via the vasculature CD8+ T cells first establish weak interactions through selectin based adhesions, likely mediated by $\mathrm{P}$ and E-selectin binding to PSGL-1 on the T cell (62, 79). These weak interactions slow down the leukocyte, inducing a slow-rolling behavior (Figure 2). Slow-rolling leukocytes subsequently interact with surface bound chemokines on the endothelium using a specific repertoire of chemokine receptors expressed by the cytotoxic $\mathrm{T}$ cell. A major chemokine receptor expressed by activated tumor infiltrating leukocytes (TILs) is CXCR3, which has been found on many CD8+ T cells that infiltrated breast, colon and melanoma tumors (31, 80-84). CXCR3 recognizes CXCL9 (Mig) and CXCL10 (IP10) which is presented on the inner lining of cancer vasculature. CXCR3 binding to CXCL9 and CXCL10 activate integrins (e.g., VLA-4) expressed on the cell surface of CD8+ T cells. Activated VLA-4 (also known as $\alpha 4 \beta 1$ ) enables transient interactions with VCAM-1

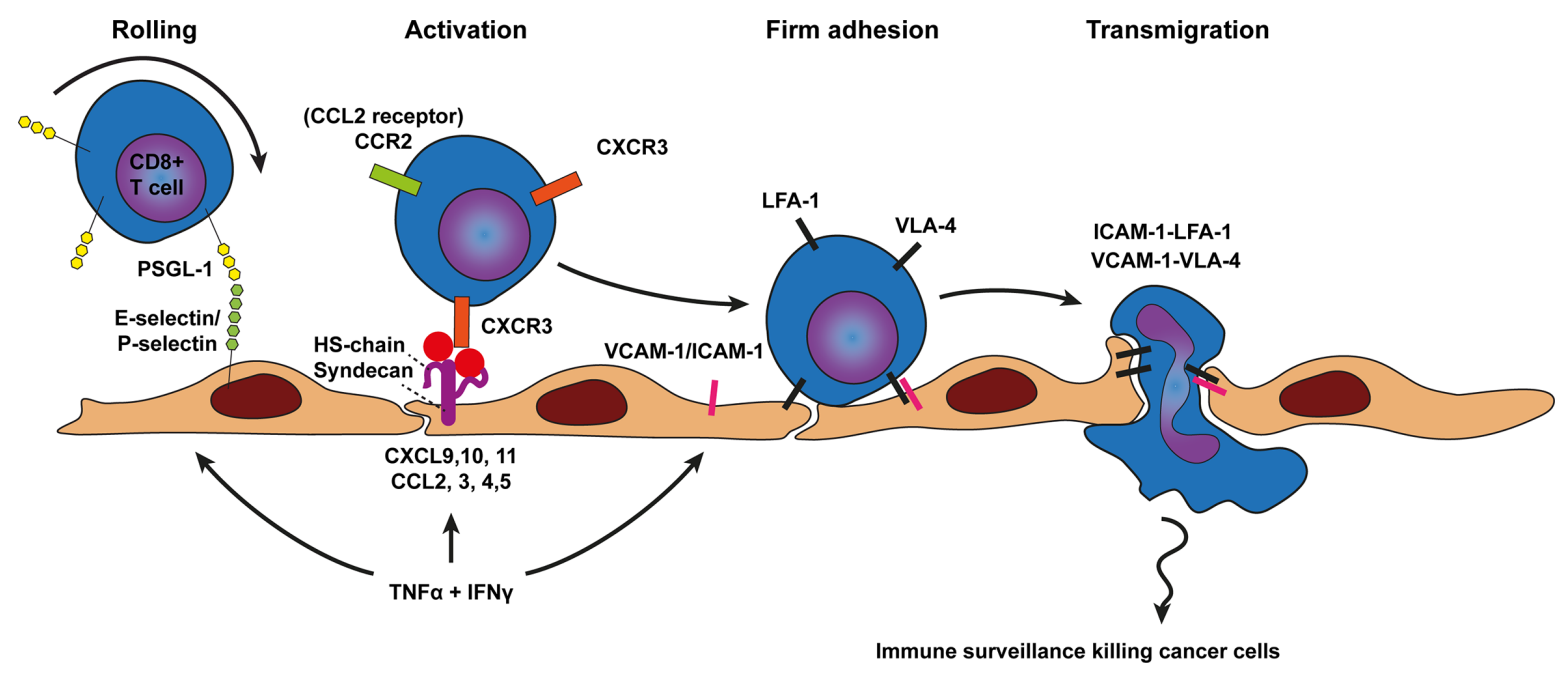

FIGURE 2 | Model of CD8+ T cell trafficking across cancer endothelium. Transmigration of CD8+ T cells across cancer endothelium is initiated by a tethering and rolling behavior which dependents on E-selectin and P-selectin binding to most likely P-selectin glycoprotein ligand 1 (PSGL1) on CD8+ T cells. CD8+ T cell activation, shown in the next step, occurs predominantly through the CD8+ T cell attracting chemokines CCL2, CXCL9, 10, and 11 which are presented on the endothelium by heparan sulfate (HS) to the chemokine receptors on CD8+ T cells (e.g., CCR2 and CXCR3). Heparan sulfate is depicted here as the heparan sulfate proteoglycan (HSPG) syndecan but other HSPGs might also be involved. Chemokine presentation activates CD8+ T cell integrins (i.e., LFA-1 and VLA-4) and results in more stable CD8+ T cell adhesion via LFA-1-ICAM-1 and VLA-4-VCAM-1 binding. Firm adhesion is followed by transendothelial migration which also involves LFA1-ICAM-1 and VLA-4-VCAM-1 interactions. TNF- $\alpha$ and INF $\gamma$ derived from various sources in the tumor microenvironment result in concomitant upregulation of cell adhesion molecules as well as presentation of CD8+ T cell specific chemokines by HS on the endothelium. 


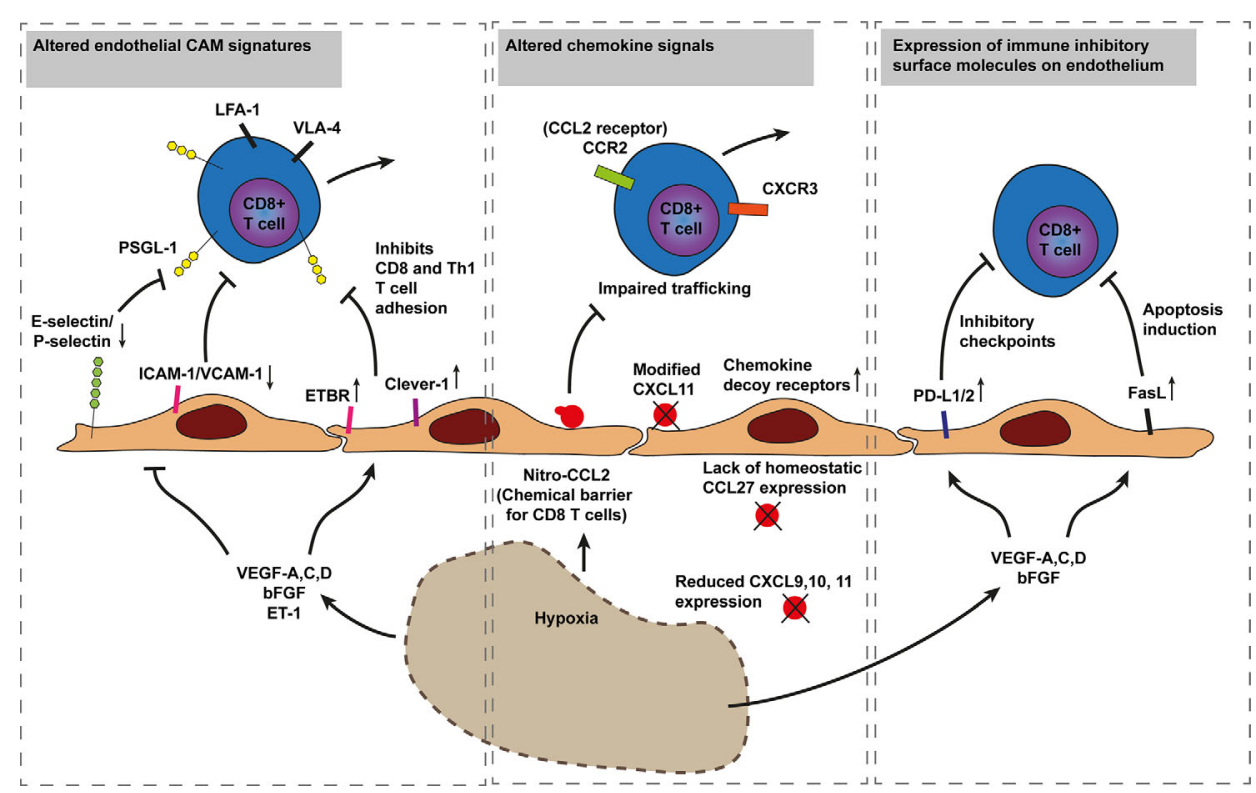

FIGURE 3 | Model of cancer immune evasion through inhibition of cytotoxic T cell recruitment. Hypoxia driven angiogenesis impairs CD8+ T cell trafficking in three established ways. The first mechanism involves inhibition of T cell adhesion through downregulation of endothelial E-selectin/P-selectin, ICAM-1, and VCAM-1 or increased expression of T cell repelling molecules such as ETBR and Clever-1 by various hypoxia induced factors (i.e., VEGF-A,C,D, bFGF, and ET-1). The Second involves altered chemokine expression and chemical barriers. For instance, nitrosylation of CCL2 by reactive nitrogen species blocks CD8+ T cell recruitment while improving recruitment of MDSCs. Additionally, a lack of CD8+ T cell specific chemokines or the increased expression of chemokine decoy receptors, scavenging away CD8+ T cell recruiting chemokines, impair CD8+ T cell tumor infiltration. The third mechanism occurs through immunosuppressive barriers as increased hypoxia and angiogenesis modulatory factors increase endothelial PD-L1/2 and FasL expression inducing T cell exhaustion and apoptosis, respectively. Endothelin B receptor (ETBR), common lymphatic endothelial, and vascular endothelial receptor-1 (Clever-1, also known as stabilin-1). Programmed death-ligand 1 (PD-L1), Fas ligand (FasL), P-selectin glycoprotein ligand 1 (PSGL1).

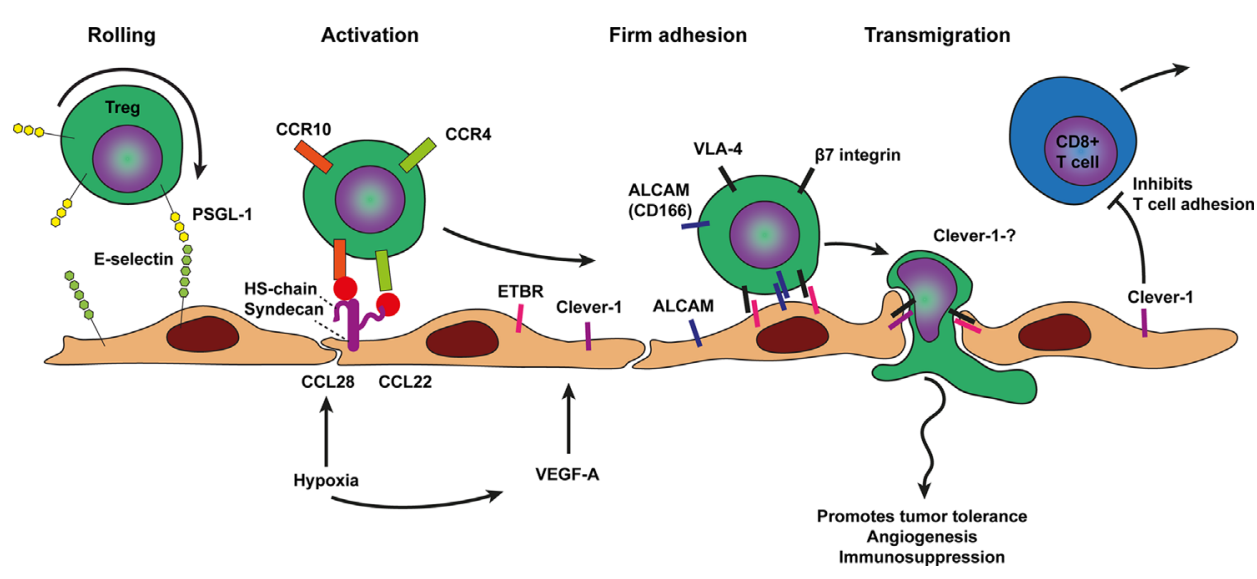

FIGURE 4 | Model of T regulatory cell trafficking across cancer endothelium. The selective trafficking of Treg cells across cancer endothelium is initiated by a tethering and rolling behavior which dependents on E-selectin binding to most likely P-selectin glycoprotein ligand 1 (PSGL1) on Treg cells. Treg cell activation, shown in the next step, involves the hypoxia induced chemokines CCL28 and CCL22 which are presented on the endothelium by heparan sulfate (HS) to the chemokine receptors on Treg cells, i.e., CCR10 and CCR4 respectively. Heparan sulfate is depicted here as the heparan sulfate proteoglycan (HSPG) syndecan but other HSPGs might also be involved. Chemokine receptor engagement activates Treg cell integrins most likely VLA-4 and $\beta 7$ integrin which results in more stable Treg cell adhesion via Clever-1, ALCAM, and ETBR binding. The exact ligands for ALCAM, Clever-1, and ETBR are not well described. Firm adhesion is followed by transendothelial migration which likely also involves Clever-1 and ETBR. VEGF-A derived from various sources in the tumor microenvironment and hypoxia may result in concomitant upregulation of cell adhesion molecules as well as presentation of Treg cell specific chemokines by HS on the endothelium. Tumor infiltrated Treg cells promote tumor tolerance, angiogenesis, and immunosuppression. 


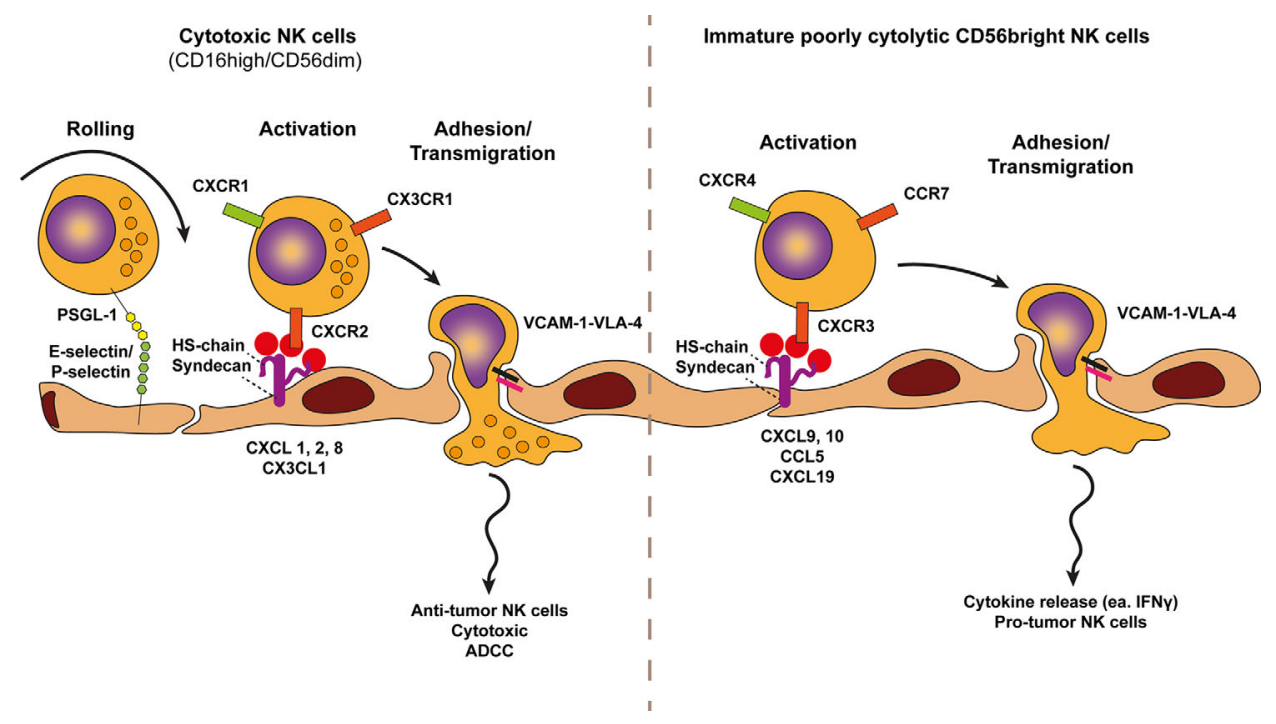

FIGURE 5 | Model of NK cell trafficking across cancer endothelium. A conventional view on NK cells subsets defines two NK cell types, the cytotoxic CD56dimCD16pos and the immature cytokine secreting CD56brightCD16low/neg NK cell variants. The selective trafficking of both NK cell subsets across cancer endothelium are proposed to involve E-selectin and P-selectin binding to most likely P-selectin glycoprotein ligand 1 (PSGL1) on NK cells, initiating a tethering and rolling behavior. Subsequent activation of each NK cell type occurs through subtype specific chemokines presented by heparan sulfate (HS) on the endothelium. Heparan sulfate is depicted here as the heparan sulfate proteoglycan (HSPG) syndecan but other HSPGs might also be involved. The chemokine receptors of cytotoxic (anti-tumor) NK cells, i.e., CXCR2, CXCR1, and CX3CR1 are activated by CXCL1,2,8 and CX3CL1 gradients whereas the chemokine receptors of immature cytokine producing NK cells (pro-tumor), i.e., CXCR4, CCR7, and CXCR3 are activated by increased presentation of CXCL9/10, CXCL19/21, and CCL5 gradients. Chemokine presentation activates NK cell integrins (i.e., VLA-4) and results in more stable NK cell adhesion via VLA-4-VCAM-1 binding. Firm adhesion is followed by transendothelial migration which also involves VLA-4-VCAM-1 interactions.

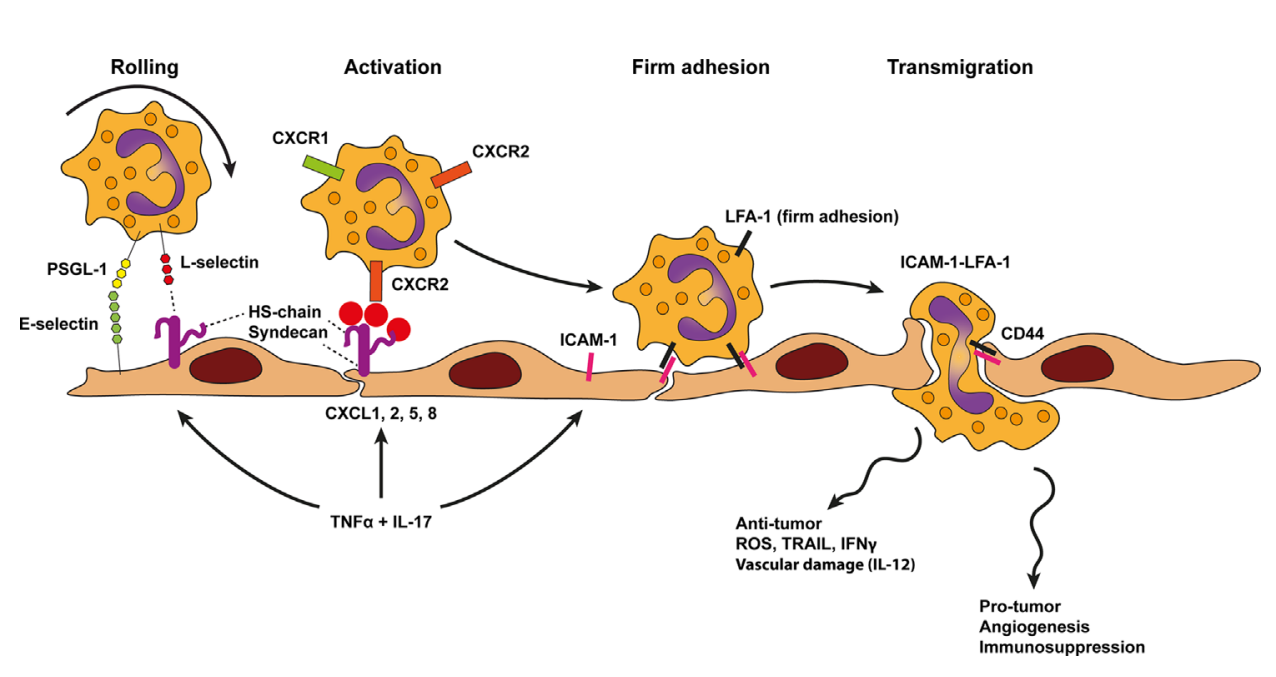

FIGURE 6 | Model of neutrophil trafficking across cancer endothelium. Neutrophil diapedesis in the context of cancer likely relies on E-selectin and ligands, such as P-selectin glycoprotein ligand 1 (PSGL1), on neutrophils which initiate rolling on the endothelium. Rolling is further stabilized by lymphocyte (L)-selectin binding to endothelial-cell heparan sulfate (HS). Heparan sulfate also presents neutrophil specific chemokines such as CXCL1, 2, 5, 8 to chemokine receptors on neutrophils (i.e., CXCR1 and CXCR2). This process activates neutrophil integrins and results in more stable leukocyte adhesion via LFA-1-ICAM-1 binding, followed by transendothelial migration using the same molecules. TNF- $\alpha$ and IL-17 derived from various sources in the tumor microenvironment result in concomitant upregulation of cell adhesion molecules as well as presentation of neutrophil specific chemokines by HS on the endothelium. In contrast to inflammation neutrophil trafficking across cancer endothelium might be Mac-1 independent. Moreover, an additional role for homotypic CD44 interactions have been proposed to guide transmigration. 


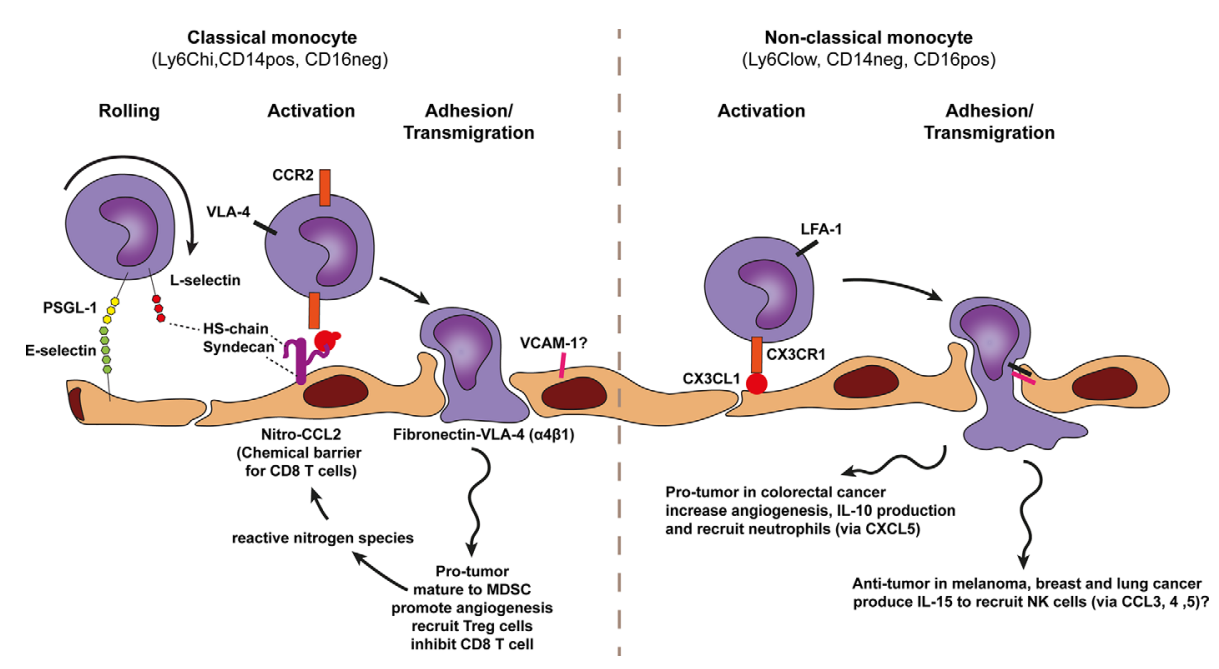

FIGURE 7 | Model of monocyte trafficking across cancer endothelium. A conventional view on monocyte subsets defines two monocyte types, the classical monocyte (Ly6Chi CD14pos CD16neg and the non-classical monocyte Ly6Clow CD14neg CD16pos. Both subsets show anti-tumor as well as pro-tumor effects which are context-dependent. The selective trafficking of both monocyte types are proposed to involve E-selectin binding to most likely P-selectin glycoprotein ligand 1 (PSGL1) on monocytes, initiating a tethering and rolling behavior, which under some conditions also involves lymphocyte (L)-selectin. L-selectin may stabilize rolling by binding to endothelial-cell heparan sulfate (HS). Subsequent activation of each monocyte type occurs through subtype specific chemokines presented by heparan sulfate (HS) on the endothelium. Heparan sulfate is depicted here as the heparan sulfate proteoglycan (HSPG) syndecan but other HSPGs might also be involved. The CCR2 chemokine receptor on classical monocytes is proposed to be activated by nitrosylation modified-CCL2 (activation can also performed by other additional chemokines) whereas non-classical monocytes are proposed to be activated in a CX3CR1-CX3CL1 dependent manner. Chemokine receptor engagement activates monocyte integrins. For classical monocytes this is most likely VLA-4 and for non-classical monocytes LFA-1 has been proposed which results in more stable monocyte adhesion via VCAM-1 and ICAM-1 binding, respectively. Classical monocytes might also bind exposed fibronectin directly via VLA-4. Classical monocytes are able to polarize to MDSCs and promote angiogenesis and production of reactive nitrogen species.

expressed on the cell surface of cancer endothelium supporting adhesion and transmigration (Figure 2).

Solid tumors expressing CXCL9 and CXCL10 recruited more CD8 T cells and showed better response to immunotherapy (85, 86). There are also tumors in which CXCL9 and 10 are low, which may explain why some tumors have low levels of CD8 T cell infiltration $(80,82)$. In addition to the C-X-C motif containing chemokines, $\mathrm{T}$ cells are predominantly recruited in some tumors via chemokines C-C motif ligands including CCL2, CCL3, CCL4, and CCL5 (80). Of these chemokines, CCL2 has been shown to increase homing of chimeric antigen receptor $\mathrm{T}$ cells (CAR T cells) that express functional CCR2 (receptor for CCL-2) (87).

Furthermore, cytokines may also modulate CD8 T cell trafficking as cytokines released by immune or cancer cells have shown to affect the expression of selective chemokines and CAMs at the surface of cancer endothelium. For instance, TNF $\alpha$ is known to increase endothelial adhesion molecules, in particular E-selectin, ICAM-1 and VCAM-1 (88). However, TNF alone has limited influence to enhance $\mathrm{T}$ cell entry into tumors this requires the presence of additional cytokines/chemokines. For instance interferon gamma (IFN $\gamma$ ) a key effector molecule released by activated cytotoxic $\mathrm{T}$ lymphocytes. Interestingly, the combination of TNF and IFN $\gamma$ amplifies endothelial ICAM-1 and VCAM-1 surface expression and simultaneously provides selectively to CD8+ $\mathrm{T}$ cell recruitment by inducing several chemokines specific for CD8+ T cells including CXCL9/10/11 and CCL5 (89-91). Several studies have examined which endothelial adhesion molecules enable infiltration of effector CD8+ T-cells into tumors, either directly using genetic knockout models (and blocking antibodies) or as a correlation (10, 30, 31, 92-97). Increased ICAM-1 and VCAM-1 expression by the tumor vasculature in response to the pro-inflammatory agent $\mathrm{CpG}-\mathrm{ODN}$ correlated with improved CD8+ $\mathrm{T}$ cell trafficking in a mouse model of pancreatic islet cell carcinoma (RIP1-Tag5) (94). In addition, in glioblastoma increased infiltration of CD8 $+\mathrm{T}$ cells also correlated with the expression of ICAM-1 and VCAM-1 on the vessel surface (95) Either, ICAM-1 and VCAM-1 blocking antibodies reduced $\mathrm{T}$ cell infiltration. Combined ICAM-1/VCAM-1 blockade showed the strongest impairment of $\mathrm{T}$ cell infiltration in glioblastoma (95). Furthermore, analyses of partly rejected B16/BL6 melanoma tumors revealed increased expression of ICAM and VCAM by the tumor vasculature, providing support for the idea that expression of these molecules strongly correlates with immune cell infiltration and tumor rejection (30). LFA-1 deficient mice failed to reject immunogenic MC57 fibrosarcoma tumors showing an important role for LFA-1 in CD8+ T cell recruitment and tumor rejection (96). Moreover, in a model for ovarian carcinoma and fibrosarcoma VLA-4-VCAM-1 as well as LFA-1-ICAM-1 interactions have been shown to mediate $\mathrm{T}$ cell infiltration in response to IL-12 treatment (92). In a separate ovarian cancer study anti-ICAM-1 blocking antibodies only partly blocked CD8+ T cell infiltration, suggesting that additional molecules like VCAM-1 may mediate CD8+ T cell extravasation as well (10). In other studies, the infiltration of 
CD8+ T cells was shown to be mediated by either ICAM-1 or VCAM-1 alone. In a study that combined vaccination with VEGF receptor tyrosine kinase (RTK) inhibitor, in a M05 mouse breast cancer model, it was shown that VCAM-1 blocking antibodies or blocking the CXCR3 receptor impaired CD8+ T cell infiltration and therapeutic efficacy (31). Evaluating ICAM-1 expression in a pancreatic islet cell carcinoma (RIP1Tag5 model), a colorectal cancer model (CT26) and B16-OVA tumors showed that extravasation of CD8+ T cells was Eselectin, P-selectin and ICAM-1 dependent, which could be blocked using corresponding blocking antibodies (93). The lack of CD8 T-cell infiltration into subcutaneous B16-OVA melanoma was confirmed in ICAM-1-/- mice (93), although conflicting it was shown that $\mathrm{T}$ cell penetration into B16 melanoma did not differ between wild-type and ICAM-1-/mice (98). Moreover, also in models of pancreatic and hepatocellular cancer no significant differences in CD8+ T cell adhesion and infiltration were found in ICAM-1 and MAC-1 deficient mice. Instead an important role for LFA-1 was found (97). Perhaps in pancreatic and hepatocellular cancer LFA-1 mediated CD8 $+\mathrm{T}$ cell extravasation via its other ligands including ICAM-2, ICAM-3, ICAM-4, ICAM-5, and JAM-A (99), which might play an important role to establish firm adhesion to cancer endothelium Together this supports a model for CD8+ $\mathrm{T}$ cell transmigration across cancer endothelium that occurs predominantly through the CD8+ $\mathrm{T}$ cell attracting chemokines CCL2, CXCL9, and CXCL10, as well as via CD8+ T cell integrins, LFA-1 and VLA-4, and endothelial E-selectin, ICAM-1 and VCAM-1. The direct role of VCAM-1, ICAM-1, and ligands for CXCR3 or other chemokine receptors in mediating $\mathrm{T}$-cell entry into additional murine and human tumors and the concomitant effects on other immune subtypes still needs to be thoroughly examined.

\section{Cancer Immune Evasion Through Inhibition of Cytotoxic T Cell Recruitment}

The direct effects of hypoxia, abnormal vasculature and hypoxia induced angiogenic factors such as VEGF-A, C, D, bFGF, EGFL7 have profound immunosuppressive effects and block $\mathrm{T}$ cell infiltration in tumors in various ways (Figure 3). First, angiogenic factors reduce endothelial VCAM-1 expression which limits $\mathrm{T}$ cell infiltration $(76,77)$.

Second, T cell trafficking to cancer is blocked through several mechanisms that interfere with chemokine signaling. For instance, $\mathrm{T}$ cell infiltration has been shown to be blocked by chemokine decoy receptor expression on tumor vessels (like DARC) that scavenge the CD8+ $\mathrm{T}$ cell recruiting chemokines CCL2 and CCL5 (100). Chemokine decoy receptors can also increase trafficking of immunosuppressive cells, for instance through downregulation of chemokine decoy receptor D6 that normally keeps CCL22 expression in check, increasing Treg cell recruitment (101). Moreover, CD8+ T cell infiltration can also be impaired through VEGF-A-mediated reduction of CD8+ T-cell recruiting chemokines CXCL9, 10, and 11. Reduced chemokine presentation can occur through downregulation or proteolytic processing as has been shown for CXCL11, which is an important chemokine recruiting CXCR3 expressing effector T cells. Dysfunctional CXCL11 impairs binding and signaling of the chemokine, ultimately reducing lymphocyte infiltration in tumors (102). Furthermore, loss of homeostatic chemokine expression can interfere with $\mathrm{T}$ cell infiltration as well. In skin tumors, loss of CCL27, a chemokine constitutively expressed by normal keratinocytes, impaired T-cell homing to cutaneous tumors accelerating tumor outgrowth in a tumor mouse model of B16F10 melanoma (12).

In addition, interference with $\mathrm{T}$ cell attracting chemokines has also been described to involve nitrosylation. In response to reactive nitrogen species (RNS) tumor cells modify CCL2 intro nitrosylated CCL2. Nitro-CCL2 recruits monocyte derived suppressor cells and repels trafficking of cytotoxic $\mathrm{T}$ cells and Th1 effector cells, confining $\mathrm{T}$ cells in stromal regions that surround cancers cells (13).

Another mechanism of endothelial anergy (lack of responsiveness) involves the binding of endothelin-1 to endothelin $\mathrm{B}$ receptor (ETBR), which prevents $\mathrm{T}$ cell adhesion to cancer endothelium, even in the presence of the inflammatory cytokine TNF $\alpha(10,103)$. In oesophageal squamous cell carcinoma high ETBR expression correlated with angiogenesis and lower survival rates (104).

Finally, cancer endothelial cells are able to increase FasL expression in response to VEGF-A. Upregulation of FAS ligands on cancer endothelium has been suggested to induce $\mathrm{T}$ cell apoptosis (11). In addition to Fas ligands, cancer endothelium can also express increased levels of the immune inhibitory checkpoints PD-L1 and PD-L2 (26). The expression of PD-L1/2 may initiate T cell anergy and exhaustion even before entering the tumor microenvironment.

\section{T Regulatory Cell Trafficking Across Cancer Endothelium}

As outlined previously, tumor growth results in hypoxia, which inducesangiogenesis in tumors. Because angiogenic tumor vessels are often dysfunctional and not well perfused angiogenesis in tumors is likely to result in more hypoxia. These hypoxic conditions in turn promote the recruitment of $\mathrm{T}$ regulatory cells (Treg cells). which promotes tolerance and angiogenesis to support tumor growth and dissemination (23). L-selectin expression is required for proper trafficking and distribution of Tregs cells under physiological conditions (105). In an inflammatory model Tregs have been shown to perform rolling under high shear stress using tether and sling formation and the authors predicted that Treg cells will also show P- and Eselectin-dependent homing to sites of inflammation (106). The precise involvement of selectin based Treg cell rolling in cancer recruitment requires further investigation. Treg cells express CCR4 and are recruited into the tumor micro environment in response to CCL22, which is produced mainly by macrophages and tumor cells (25) (Figure 4). Another chemokine shown to recruit Treg cells is the hypoxia related chemokine CCL28 (23) which may reinforce the vicious cycle of hypoxia induced angiogenesis resulting in more abnormal vasculature and hypoxia. In addition, Tregs exposed to hypoxia show increased 
CXCR4 surface expression which in turn can interact with its ligand stromal-derived-factor-1 (SDF-1 also called CXCL12) to mediate infiltration of Treg cells into breast cancer (107).

Several angiogenic factors including VEGF-A,C,D, bFGF, and Egfl7, increased expression of the ETBR $(10,103)$. Glioblastomas with higher numbers of ETBR-expressing vessels showed lower infiltration by cytotoxic $\mathrm{T}$ cells and higher numbers of regulatory $\mathrm{T}$ cells. Cytotoxic T cells infiltrated around ETBR-negative blood vessels, but were absent around vessels expressing ETBR (28). The common lymphatic endothelial and vascular endothelial receptor-1 (Clever-1, also known as stabilin-1) also selectively mediates transmigration of Tregs across cancer endothelium. In tumors, VEGF-A induces upregulation of Clever-1, recruiting Tregs while repelling CD8 T cell binding (27). Clever-1 knockout mice show impaired Treg trafficking while trafficking of CD8 T cells was unchanged (108). Clever-1 knockout mice also had impaired tumor migration via lymphatics (108).

In addition to ETBR and Clever-1, several adhesion molecules have been described to regulate selective transmigration of Tregs across cancer endothelium and might be cancer type specific. In pancreatic carcinoma, selective transmigration of Tregs involved the mucosal adressin cell adhesion molecule-1 (MAdCAM-1), VCAM-1, E-selectin, and activated leukocyte cell adhesion molecule (ALCAM, also known as CD166). Blocking antibodies against the ligands $\beta 7$ integrin, L-selectin, and CD166 specifically expressed on the surface of Treg cells impaired Treg trafficking (29). In contrast, blocking antibodies against P-selectin, ICAM-1 and ICAM-2 did not block Treg transmigration (29).

\section{NK Cell Trafficking Across Cancer Endothelium}

NK cells play an active role in immune surveillance which is particularly effective for hematological tumors, early stage solid tumors and metastatic cells circulating in the blood $(109,110)$. Conversely, NK cells are less effective in controlling advanced solid tumors that are characterized by an abundant variety of immunosuppressive factors typical for a tumor microenvironment. These include the direct effects of hypoxia and angiogenesis factors on cancer and immune cells increasing the amount of surface expressed immune inhibitory checkpoints, such as PD-L1 and B7$\mathrm{H} 3(9,111)$ as well as immunosuppressive cytokines such as TGF $\beta$ released by tumor cells and tumor associated macrophages (112-114).

Another aspect that impacts the performance of NK cell mediated immune surveillance is the low frequency and/or type of NK cell recruited to the tumor. The two major functions of NK cells, i.e., cytokine production and cytotoxic activity are conventionally associated with distinct NK cell subsets. Whereas cytotoxic activity is mostly confined to NK cell variants identified as CD56dimCD16pos, production of cytokines, i.e., IFN $\gamma$ occurs mainly by immature CD56brightCD16low/neg NK cells (115). In line with tumors escaping immune surveillance, cytotoxic CD56dimCD16pos NK cells are sporadically found in advanced solid tumors whereas immature CD56brightCD16low/neg NK cell variants represent the majority of tumor infiltrated NK cells.
The adhesion of NK cell variants to cancer endothelium shows similarities to that of CD8 T cells, starting with selectin-induced rolling, followed by VCAM-1-VLA-4 mediated adhesion and transmigration (Figure 5). Mice deficient in E- and P-selectin were defective in NK cell recruitment to subcutaneous Lewis lung carcinoma (LLC) and MC38 tumors, showing the relevance of these molecules in NK cell tumor infiltration (116). IL-2-induced NK cell infiltration into lung, liver and subcutaneous B16 melanoma was mediated by endothelial VCAM-1 interacting with VLA-4 on NK cells. NK cell infiltration was neither blocked by anti-ICAM-1 nor LFA-1 blocking antibodies (117). Selective recruitment however, is determined by distinct chemokines presented at the surface of cancer endothelium. Immature protumor CD56brightCD16low/neg NK cell recruitment occurs via increased expression of CXCL9, CXCL10, CXCL19, CXCL21, and CCL5, and reduced expression of CXCL2, CX3CL1, CXCL1, and CXCL8 (118). Conversely, CXCL2, CX3CL1, CXCL1, and CXCL8 are important recruiters of cytotoxic CD56dimCD16pos NK cells into the TME. Of note, CXCL9 and CXCL10 recruiting pro-tumor immature CD56brightCD16low/neg NK cells are also involved in the recruitment of cytotoxic CD8 T cells.

\section{Neutrophil Trafficking Across Cancer Endothelium}

In a physiological setting, neutrophils play a vital role to counter microbial infections and have supportive functions during wound healing. In cancer, however, neutrophils have shown to support tumor growth and progression through angiogenesis induction and immunosuppressive functions (119, 120). In general, neutrophil transmigration across cancer endothelium resembles that of inflammation. Heparan sulfate deficiency in mice showed reduced L-selectin and chemokine-mediated neutrophil trafficking in an inflammatory model, showing two important functions of endothelial heparan sulfate: acting as a ligand for L-selectin and presenting chemokines at the luminal surface of the endothelium $(63,64)$. Furthermore, the use of Lselectin and E-selectin deficient mice in lung and CRC models have shown that selectin-mediated recruitment of neutrophils support cancer metastasis $(121,122)$. In inflammatory settings the integrin LFA-1 (CD11a/CD18, $\alpha \mathrm{L} \beta 2)$ is required to establish firm adhesion and transmigration of neutrophils across vascular beds. Mice lacking CD18 ( $\beta 2$ integrin) have impaired infiltration of neutrophils in solid tumors, indicating that this integrin is also involved in neutrophil migration into tumors (123). A study examining the recruitment of CD11bpos myeloid cells in response to tissue damage and hypoxia in irradiated tumors corroborated the importance of CD18 in myeloid recruitment, whereas CD11b was redundant (124). Together this supports that neutrophil interaction with the vasculature are predominantly regulated by LFA-1-ICAM-1 interactions (Figure 6).

IL-17, the signature cytokine expressed by $\gamma \delta \mathrm{T}$ Cells and Th17 cells, was recently associated with shaping neutrophil recruitment to tumors $(125,126)$. The combined activation of endothelial cells by TNF and IL-17 synergistically increased Pselectin, E-selectin, and ICAM-1, which enhanced neutrophil 
specific rolling and adhesion to the vasculature. TNF in combination with IL-17 stimulation dampened VCAM-1 levels compared to TNF alone, whereas ICAM-1 levels remained highly expressed on the endothelium (90). Importantly, IL-17 and TNF synergistically increased the neutrophil-recruiting chemokines CXCL1 (GRO- $\alpha$ ), CXCL2 (MIP2 $\alpha$ ), CXCL5 (LIX), and induced secretion of GM-CSF and G-CSF to mobilize myeloid cells including neutrophils from the bone marrow into the circulation $(90,127)$. Another study showed that Ly6Clow monocytes recruited Ly6G+ neutrophils via CXCL5 (128).

The anti-tumor functions of neutrophils are controversial, and substantial evidence suggest that the anti-tumor activity of neutrophils is context dependent. In pancreatic ductal adenocarcinoma the CXCR2-CXCL5 axis increased infiltration of neutrophils, which promoted tumor growth (128). Conversely, in esophageal squamous cell carcinoma IL-17 stimulated CXCL2 production by tumor cells, which is also associated with increased infiltration of neutrophils. However, in this context neutrophil infiltration induced anti-tumor effects since IL-17 potentiated the direct killing capability of neutrophils by enhancing the production of cytotoxic molecules, including reactive oxygen species (ROS), MPO, TNF-related apoptosisinducing ligand (TRAIL), and IFN $\gamma$ (129). Another example of beneficial anti-tumor neutrophils has been shown in the context of early stage epithelial carcinogenesis. Hypoxia induced expression of CXCL1 (GRO- $\alpha$ ), CXCL2 (MIP2 $\alpha$ ), CXCL5 (LIX) recruited anti-tumor neutrophils, which inhibited tumor growth by inducing tumor cell detachment from the basement membrane (130). Neutrophils have also been implicated to induce vascular damage, resulting in ischemic hemorrhagic necrosis and tumor rejection, for instance in response to intratumoral IL-12 injections (131). This type of neutrophil mediated tumor death seemed to play a crucial role in the rejection of subcutaneous tumors but not in lung metastasis (131). Furthermore, DC101 (anti-VEGFR2) enhanced neutrophil and macrophage infiltration, and in combination with a glucuronide prodrug had increased anti-tumor activity in experimental mouse models (132). In a co-culture of UKFNB-4 neuroblastoma tumor cells and human umbilical vein endothelial cells (HUVEC) it has been shown that direct tumor-endothelial cell-cell contact promotes downregulation of endothelial CD44 receptor expression, impairing neutrophil binding $(133,134)$. How endothelial CD44 inhibition may repel an effective anticancer attack by neutrophils was not investigated.

\section{Monocyte Trafficking Across Cancer Endothelium}

Two monocyte type subsets have been identified, i.e., classical monocytes (Ly6Chi CD14pos CD16neg) and non-classical monocytes (Ly6Clow CD14neg CD16pos) (135). Both subsets show anti-tumor as well as pro-tumor effects, which are contextdependent (135). Classical monocytes mainly support tumor growth and metastasis through VEGF-A release, which promotes angiogenesis (136-138) and worsens clinical outcome (139). Classical monocytes have also been associated with anti-tumor effects $(138,140)$.

Classical monocytes express high levels of the chemokine receptor, CCR2 (136). CCR2 mediates monocyte activation upon recognition of immobilized CCL2 at the endothelium (136), which is mediated by TNF (141). This CCR2-CCL2 axis has shown to recruit angiogenic classical monocytes in PyMT spontaneous breast carcinoma, KCKO pancreatic carcinoma, and MC38 colorectal carcinoma (136, 139, 142, 143) (Figure 7). In a model for pancreatic carcinoma and liver metastasis CCR2 deficiency or CCR2 blockade has shown to impair classical monocyte recruitment, angiogenesis inhibition and relief of immunosuppression $(139,143)$. In addition, CCR2 inhibition decreased the number of tumor associated MDSCs and improved anti-PD-1 therapy in resistant murine gliomas (144).

The use of E- and L-selectin-deficient mice in a lung cancer model (LLC) and CRC model (MC-38) has shown that selectinmediated recruitment of monocytes and macrophages supports tumor metastasis $(121,122,145)$. This indicates the importance of E-selectin (ligand for, e.g., PSGL-1) and L-selectin (ligand for, e.g., GlyCAM-1, CD34, etc.) for myeloid cell recruitment in cancer (62).The integrin VLA-4 has been shown to regulate recruitment of classical monocytes to tumors promoting angiogenesis (146). VLA4 is known to interact with VCAM-1. However in the context of vascular abnormalities in cancer, monocytes may use VLA-4 to bind to fibronectin, as the disruptive endothelium in cancer contains many intercellular gaps, hereby exposing fibronectin (Figure 7). Indeed, VLA-4 has shown to be important for selective homing of monocytes to tumors (146).

An interesting phenomenon affecting leukocyte trafficking and immunosuppression in cancer involves the effects of hypoxia on myeloid cells. Hypoxia causes myeloid cells to produce arginase (ARG) and nitric oxide synthase. Arginase inhibits effector $\mathrm{T}$ cell function inducing immunosuppression (119, 147). Moreover, nitric oxide synthase is an important producer of peroxynitrate, a molecule important to form reactive nitrogen species (RNS), affecting selective trafficking of leukocytes into tumors. RNS have been implicated in chemokine nitrosylation, a posttranslational modification forming chemical barriers for certain leukocyte subsets. Nitrosylated CCL2 forms a physical barrier for cytotoxic T cells and Th1 effector cells (Figure 7). Conversely, nitro-CCL2 recruits MDSCs supporting angiogenesis and tumor growth (13). CCR2 knockout mice fail to recruit MDSC to cancers (148). High levels of CCL2 have been found in breast, gastric and ovarian cancers, which correlated with MDSC infiltration (148).

In contrast to CCR2-dependent recruitment of classical monocytes, the mobilization and homing of non-classical monocytes (also known as patrolling monocytes) to tumors involves the chemokine receptor CX3CR1 (149) (Figure 7). CX3CR1 mediates the migration of non-classical monocytes through CX3CL1 recognition on cancer endothelium. In melanoma, breast and lung cancer non-classical monocytes show anti-tumor effects predominantly through recruitment of cytotoxic NK cells (150-153). Conversely, in colorectal cancer, 
non-classical monocytes promoted tumor growth through induction of angiogenesis and immune suppression (51, 52, 154). Interestingly, these non-classical monocytes also release CXCL5 to recruit neutrophils and produce IL-10, inhibiting adaptive immunity (52).

\section{TUMOR DISSEMINATION VIA VASCULAR AND LYMPHATIC NETWORKS}

Pathological angiogenesis in cancer forms an abnormal tumor vascular network. The connection of this abnormal vascular network to the vascular system provides a conduit for cancer cells to spread over the body, facilitating tumor metastasis $(155,156)$. Abnormal tumor vessels are characterized by an immature morphology, meaning lower pericyte and smooth muscle cell coverage, discontinuous endothelial cell-cell junctions, and an abnormal basement membrane $(157,158)$. Moreover, the blood flow in tumors does not always follow a constant unidirectional path, and an extensive amount of the tortuous tumor vascular network is not well perfused $(46,159)$. Despite less perfusion of tumor vessels metastasis via the blood circulation occurs more frequently than distant metastasis via the lymphatics (155). Pericytes are important supportive stromal cells for endothelial cell function and monolayer integrity. Consequently, the lack of pericyte coverage cause improper and loose endothelial cell-cell contacts, leaky, and permeable vessels which increase the number of tumor cells to metastasize via the blood stream (158). Dysfunctional angiogenic vasculature in tumors generally increases hypoxia, which can further promote cancer cell motility and metastasis through the activation of epithelial to mesenchymal transition (EMT) $(160,161)$. EMT mechanisms decrease epithelial cell-tocell junctions and increase cancer cell motility, enhancing invasiveness and cancer escape. Downregulation of E-cadherin, an important molecule for stability of cell-cell contacts, and upregulation of the transcriptional factors Snail1, Snail2, Slug, and Twist are described as main drivers for EMT $(161,162)$. In addition, hypoxia related TGF- $\beta 3$ induction $(163,164)$ and Notch signaling pathways are reported as EMT promoting mechanisms as well (165).

In addition to EMT mechanisms and metastasis via the blood circulation, abnormal lymphatic vessels and lymph angiogenesis also facilitate tumor dissemination. VEGF-C and VEGF-D are key promoters of tumor-associated lymph angiogenesis, increasing lymphatic vessel diameter (166) and cancer metastasis via lymphatics (166-169). Blocking VEGF-C and VEGF-D signaling with neutralizing antibodies or soluble VEGFR3 correlated with suppressed tumor lymph angiogenesis and lymph node metastasis $(170,171)$. Moreover, the leaky nature of vessels combined with dysfunctional lymphatic drainage results in increased interstitial fluid pressure in the tumor microenvironment. Consequently, high fluid pressure drives cancer cells passively into enlarged tumor associated lymphatic vessels and supports cancer metastases to distal organs $(172,173)$. An active mechanism of tumor dissemination via lymphatics involves the chemokines
CCL21 and CCL19, which are secreted by tumor cells. In response to high fluid pressure CCL21 and CCL19 are pushed towards tumor draining lymph nodes, which are simply followed by cancer cells that sense the fluid pressure induced chemokine gradients via CCR7 (166). Altogether, the vascular network in tumors sustains a favorable niche for cancer cells to thrive and ultimately metastasize.

\section{A RATIONALE TO COMBINE IMMUNOTHERAPY WITH ANTI-ANGIOGENIC AGENTS}

Vascular abnormalities are a hallmark of most solid tumors. Targeting angiogenesis in tumors with monoclonal antibodies such as Bevacizumab (anti-VEGF) were initially aimed to starve tumors to death and prevent metastatic spread. However, the benefits of Bevacizumab used as a single agent were modest evidenced by limited tumor regression and low overall survival (174-176). The lack of durable anti-tumor responses might be attributed, in part, by compensatory mechanisms in angiogenesis pathways, including alternative angiogenesis pathways such as the Ang2 pathway (177), co-option of nearby vessels or vessel mimicry $(73,178)$. Moreover, tumors that relapsed from angiogenesis treatment showed increased expression of immune inhibitory checkpoints such as PD-L1 (179), which provides a rational to combine anti-angiogenic agents with checkpoint blockade.

As outlined, pro-angiogenic proteins have profound effects on a broad range of immune cells, which alter immune cell maturation, activity and trafficking and hereby support immune suppression and tumor immune evasion. A logical intervention to tackle the leukocyte trafficking problem and immunosuppression in cancer is to also target angiogenic tumor vessels in addition to immunotherapy. The majority of the anti-angiogenic approaches (e.g., anti-VEGF antibodies or VEGF tyrosine kinase inhibitors (TKI)) induce vessel normalization, which is characterized by increased vessel perfusion, pericyte coverage (180), increased oxygen (181-183), reduced permeability (36), regression of tortuous vasculature (184-186), reduced interstitial fluid pressure (185), and upregulation of Ang-1 gene expression (184). In addition, targeting pro-angiogenic proteins such as VEGF counteracts immunosuppressive effects on immune cells as a result of reduced hypoxia in tumors $(15,17,37)$. Furthermore, substantial evidence underscores the potential of angiogenesis inhibition to restore endothelial function allowing the infiltration of cytotoxic immune cells by improving vascular-leukocyte interactions and chemotaxis $(9,31-34,187,188)$ which overall may improve the efficacy of many immunotherapy formats.

Likewise, preclinical studies show that immune checkpoint blockade brings about anti-vascular immune responses against tumor vessels showing the synergistic potential of combining anti-angiogenic agents with immunotherapy (179, 189-191).

Anti-angiogenic agents yield a therapeutic window of vascular normalization in which new strategies can be explored 
to increase infiltration of cytotoxic immune cells improving the efficacy of immunotherapy. This may yield a better overall efficacy. The dosing of anti-angiogenic agents, however, needs to be carefully evaluated as high dose can also result in increased vessel pruning and hypoxia, mediating resistance to therapy (37, $73,177)$. Altogether, anti-angiogenic agents have the potential to reprogram the immunosuppressive TME to a microenvironment that supports anti-tumor immunity.

\section{TARGETING TUMOR VESSELS TO ENHANCE LEUKOCYTE TRAFFICKING AND IMMUNOTHERAPY}

To date, there are a handful of approaches to increase selective trafficking of leukocytes into tumors. These include antiangiogenic agents, blocking antibodies targeting key surface molecules involved in leukocyte traffic, targeted delivery of proinflammatory cytokines and nanoparticles that deliver content to silence leukocyte specific chemokine expression (Figure 8). Because tumor vasculature is very distinct from resting endothelial cells in healthy tissue, a great variety of surface molecules, commonly involving angiogenesis related proteins, are available to enable targeted therapy of tumor vessels.

\section{Anti-Angiogenic Approaches}

An established way of targeting tumors and increase leukocyte infiltration in tumors is through inhibition of angiogenesis (Figure 8A) including anti-VEGF/VEGFR2 (32-34, 179, 187, 192-195), Ang2 (190, 196), VEGF TKI (9, 31, 188, 197, 198), or Tie2 agonists (36). The majority of these anti-angiogenic approaches induce vessel normalization, which is characterized by increased vessel perfusion, pericyte coverage (180), increased oxygen (181-183), reduced permeability (36), regression of tortuous vasculature (184-186), increased leukocyte traffic (9, $31-34,187,188)$ reduced interstitial fluid pressure (185) and upregulation of Ang-1 gene expression (184).

Vascular normalization creates a window of opportunity to combine anti-angiogenic agents with other anti-cancer therapies, especially with immunotherapy $(15,17)$. As such, targeting tumor vessels with anti-angiogenic agents in combination with immune inhibitory checkpoints $(9,179,190,195,196,199-202)$, adoptive cell transfer $(34,187,193,194,197,203)$, or cancer vaccines (31-33, $188,192,198)$ has shown improved anti-cancer effects. Normalization effects of anti-VEGF on tumor vasculature can already observed as early as one day after treatment in mice and human, as more matured vessels were observed as well as reduced tortuous vessels, which had smaller diameter and were shorter in length (204). The time that the therapeutic window persists depends on the therapy dosage $(32,174)$ and on tumor origin $(19)$. At the

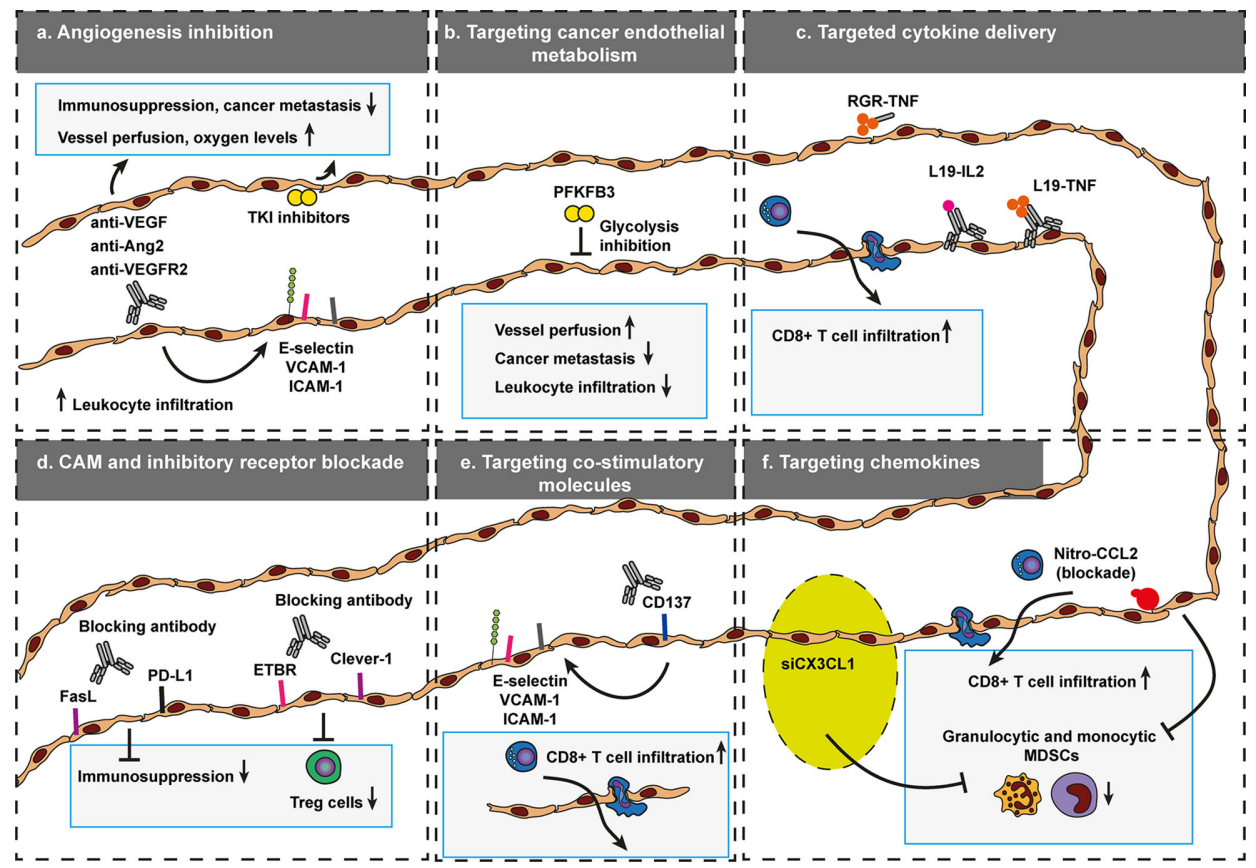

FIGURE 8 | Targeted approaches that govern selective trafficking of leukocytes across cancer endothelium. To data, a variety of vascular targeting approaches have been developed to modulate leukocyte trafficking to increase the efficacy of anti-cancer therapy. These include inhibition of angiogenesis (A), targeting cancer endothelial metabolism (B), targeted cytokine delivery (C), CAM, and immune inhibitory receptor blockade (D), targeting co-stimulatory molecules (E), and silencing of leukocyte recruiting chemokines (F). Targeting agents that affect selective trafficking of leukocytes across cancer endothelium become increasingly relevant as the success of many immunotherapy formats also depends on effective recruitment of cytotoxic or inhibition of immunosuppressive immune cells. Endothelin B receptor (ETBR), common lymphatic endothelial, and vascular endothelial receptor-1 (Clever-1, also known as stabilin-1). Programmed death-ligand 1 (PD-L1), Fas ligand (FasL). 
right dose, the window might last for about a week in mice $(32,204)$. In humans the window is suggested to last longer $(15,19)$.

Perhaps counterintuitive, extensive treatment, and high dose anti-angiogenic agents shorten the therapeutic window as this leads to enhanced vessel pruning, which leads to vascular disruption and increased hypoxia that may ultimately result in induction of alternative angiogenesis pathways such as Ang2 pathway, hereby driving therapeutic resistance $(73,177)$. This also suggests that targeting multiple angiogenic pathways simultaneously may enhance angiogenic therapeutic responses. Combined targeting of Ang2 and VEGF pathways was show to extend the normalization window $(35,205,206)$.

In addition to the effects of VEGF blockade on the tumor vasculature, single targeting of VEGF or in combination with Ang2 blockade converted the immunosuppressive environment into an immune stimulatory environment, evidenced by increased detection of M1 macrophages and increased CD8+ T cells infiltration in GL261 glioblastoma tumors (35), or in a model of MCaP0008 breast cancer (32). Furthermore, inhibition of angiogenesis and simultaneously activating the Tie2 pathway (stabilizing/strengthening endothelial junctions) normalized vessels effectively, increasing oxygen levels and diminished immunosuppression (36). Because the majority of antiangiogenic approaches relieve immunosuppression $(32,35)$ and increase leukocyte entry into tumors through normalization of tumor vessels (32), the use of anti-angiogenic therapy in combination with immunotherapy exhibits great potential to enhance tumor killing.

The potential to combine anti-angiogenic therapy with immunotherapy, in particular with checkpoint inhibitors, was corroborated by many combinations in various preclinical mouse models (Table 1) and tested in a large number of clinical phase I, II and III trials that confirm the synergistic effect of combinational therapy (Table 2). In pre-clinical studies the general outcome of combining anti-angiogenic agents with immunotherapy shows increased tumor regression and overall survival, often associated with relief of immunosuppression, evidenced by reduced presence of tumor resident MDSC and Treg cells, which often coincided with increased infiltration of CD4 and CD8 T cells (9, 31-34, 187, 188, 221). However, the majority of studies do not include metrics to show that vascular normalization is achieved. Blocking anti-VEGF in combination with checkpoint inhibition and its effects on the vasculature should be investigated in more detail in further research.

Several clinical trials corroborated the increased progressionfree survival rates found in preclinical studies. In a phase III trial, investigating the survival benefits for patients with advanced renalcell carcinoma upon dual targeting with checkpoint inhibitors and angiogenesis blockade, combined effects of pembrolizumab (antiPD-1) with axitinib (VEGFR TKI) resulted in a significantly longer overall and -progression-free survival, as well as a higher objective response rate, compared to sunitinib (VEGFR TKI) treatment alone (222). Another study (phase I), tested the combined effects of the immune checkpoint CTLA-4 (ipilimumab) and VEGF inhibition by bevacizumab on immune infiltration in metastatic melanoma patients. This study corroborated the effect of antiangiogenic agents on vessel normalization and activation, evidenced by increased E- selectin expression on intratumoral endothelial cells, which coincided with increased infiltration of $\mathrm{CD}^{+}$cytotoxic $\mathrm{T}$ cells, $\mathrm{CD}_{163^{+}}$macrophages and minimal change in Foxp $3^{+}$Treg cells (210). Moreover, a study combining bevacizumab and an antitumor vaccine, followed by adoptive T-cell transfer showed clinical benefit for recurrent ovarian cancer, including one complete response (223). Together, this data emphasizes the power to combine anti-angiogenic therapy with immunotherapy and highlight its clinical potential.

\section{Targeting Cancer Endothelial Metabolism}

In addition to the more established vascular normalizing-agents anti-VEGF or -ANG2, an emerging way of inducing vascular normalization is introduced through targeting of endothelial cell metabolism (Figure 8B). Endothelial sprouting involved in angiogenesis relies on glycolysis rather than oxidative phosphorylation for ATP production. As such blocking PFKFB3, a key molecule involved in endothelial glycolysis, reduced vessel sprouting and angiogenesis $(224,225)$. In a cancer setting, transient reduction of glycolysis by PFKFB3 blockade improved vessel normalization, impaired tumor metastasis and improved chemotherapy delivery (226). In this setting, vessel normalization was characterized as a tighter barrier with increased pericyte coverage. However, glycolysis blockade also interfered with NF$\kappa \mathrm{B}$ signaling, which reduced endothelial adhesion molecules, i.e., ICAM-1 and VCAM-1. The reduction of CAM expression reduced metastatic spread, but might also interfere with infiltration of cytotoxic effector cells. In addition, there are also dose dependent limitations of using PFKFB3 blockade. High dose PFKFB3 aggravates vessel integrity, tumor hypoxia, and metastasis, highlighting the importance of adequately dosing a glycolytic inhibitor for anticancer treatment (227). As such, future research should identify whether endothelial glycolysis blockade in combination with immunotherapy is beneficial. Moreover, further studies now investigate the potential of studying tumor endothelial cell metabolism and its heterogeneity (228).

\section{MODULATING SELECTIVE LEUKOCYTE RECRUITMENT DURING VASCULAR NORMALIZATION}

Vascular normalization with anti-angiogenic drugs or glycolysis blockade may create a therapeutic window for immunotherapy, but success of therapeutic efficacy also depends on either effective recruitment of cytotoxic immune cells or inhibition of immunosuppressive cells. Therefore, targeting agents that affect selective trafficking of leukocytes across cancer endothelium become increasingly relevant. Thus far, a couple of approaches have been developed to regulate immune cell trafficking to provide access and selectivity for some immune cell subtypes to cross the endothelial barrier (Figures 8C-F).

First, selective immune cell trafficking was regulated through targeted-delivery of cytokines using cytokine-peptide fusions or cytokines-antibody fusion, i.e., immunocytokines (Figure 8C). An promising example is the targeted delivery of low dose TNF 
TABLE 1 | Preclinical studies on combinations of antiangiogenic agents and immunotherapies.

\begin{tabular}{|c|c|c|c|c|}
\hline Immunotherapy & Antiangiogenic Therapy & Disease & Key Results & Refs \\
\hline \multicolumn{5}{|l|}{ Vaccination Studies } \\
\hline $\begin{array}{l}\text { Tumor-antigen-specific } \\
\text { picornaviral vaccination }\end{array}$ & Aflibercept (anti-VEGF) & Glioblastoma & $\begin{array}{l}\text { CD8+ T cells } \uparrow \text { Tumor progression } \downarrow \text { and } \\
\text { animal survival } \uparrow\end{array}$ & $(192)$ \\
\hline $\begin{array}{l}\text { Whole tumor cell vaccine } \\
\text { (mitomycin treated and GM-CSF } \\
\text { secreting) }\end{array}$ & DC101 (anti-mouse VEGFR2 mAb) & Breast cancer & $\begin{array}{l}\text { CD4+ and CD8+ T cells } \uparrow \text { MDSCs and Treg } \\
\text { cells } \downarrow \text { Tumor regression and animal survival } \uparrow\end{array}$ & $(32,33)$ \\
\hline $\begin{array}{l}\text { Pox virus vaccine expressing } \\
\text { CEA and three co-stimulatory } \\
\text { molecules }\end{array}$ & Sorafenib (VEGFR-TKI) & Colon cancer & $\begin{array}{l}\text { Intratumoral CD8+ T cells } \uparrow \text { and Treg cells } \\
\downarrow \text { MDSCs and Treg cells } \downarrow \text { Tumor volume } \\
\downarrow \text { Animal survival } \uparrow\end{array}$ & (198) \\
\hline OVA peptide-pulsed DC (VAC) & Sunitinib (TKI) & Melanoma & $\begin{array}{l}\text { Anti-tumor efficacyrecruitment of Type- } 1 \text { anti- } \\
\text { tumor } T \text { cells into the TME } \uparrow M D S C \downarrow \text { Treg } \downarrow\end{array}$ & (31) \\
\hline MVA/rF-CEA/TRICOM & Cabozantinib (TKI) & Colon cancer & $\begin{array}{l}\text { MDSCsf and Treg cellsf } \downarrow \text { CD4-positive and } \\
\text { CD8-positive T-cellinfiltration } \uparrow\end{array}$ & $(188)$ \\
\hline \multicolumn{5}{|l|}{ Cell Therapy Studies } \\
\hline $\begin{array}{l}\text { Anti-PMEL T cells, PMEL } \\
\text { vaccine, and IL-2 }\end{array}$ & $\begin{array}{l}\text { DC101 (anti-VEGFR2 mAb) and B20 (anti-VEGF } \\
\text { mAb) }\end{array}$ & Melanoma & $\begin{array}{l}\text { Immune cell infiltration } \uparrow \text { Tumor growth } \\
\downarrow \text { Animal survival } \uparrow\end{array}$ & $(34)$ \\
\hline $\begin{array}{l}\text { Anti-VEGFR1 chimeric antigen } \\
\text { receptor T cells }\end{array}$ & & Lung cancer & $\begin{array}{l}\text { Endothelial tube formation in vitro } \downarrow \text { Tumor } \\
\text { growth and metastasis } \downarrow\end{array}$ & $(194)$ \\
\hline $\begin{array}{l}\text { Tumor-antigen-specific CD8+ T } \\
\text { cell transfer }\end{array}$ & Sunitinib (TKI) & $\mathrm{HCC}$ & Complete tumor regression & $(197)$ \\
\hline $\begin{array}{l}\text { GM-CSF-secreting tumor cell } \\
\text { immunotherapy }\end{array}$ & sVEGFR1/R2 & $\begin{array}{l}\text { Melanoma, Colon } \\
\text { cancer }\end{array}$ & $\begin{array}{l}\text { Animal Survival } \uparrow \text { CD4+ and CD8+ tumor- } \\
\text { infiltrating } T \text { cells } \uparrow \text { Treg cellsf } \downarrow\end{array}$ & $(165)$ \\
\hline \multicolumn{5}{|l|}{ Immune Checkpoint Inhibitors } \\
\hline Anti-PD-1 mAb & Vanucizumab (Anti-Ang2 Anti-VEGFA), & $\begin{array}{l}\text { Breast cancer, } \\
\text { Melanoma, } \\
\text { Pancreatic cancer, } \\
\text { Neuroendocrine } \\
\text { cancer }\end{array}$ & Tumor growth $\downarrow$ Animal survival $\uparrow$ & $(190)$ \\
\hline Anti-PD-1 mAb & DC101 (anti-VEGFR2 mAb) & Colon cancer & $\begin{array}{l}\text { Angiogenesis } \downarrow T \text { cell infiltration } \uparrow \text { Cytokine } \\
\text { expression } \uparrow\end{array}$ & $(195)$ \\
\hline Anti-PD-1 mAb & Sunitinib (TKI) & Colon cancer & PD- $1+$ CD8+ $T$ cells $\downarrow$ Anticancer activity $\uparrow$ & (9) \\
\hline Anti-PD-L1 mAb & DC101 (anti-VEGFR2 mAb) & $\begin{array}{l}\text { Pancreatic cancer, } \\
\text { Breast cancer, } \\
\text { Glioblastoma }\end{array}$ & $\begin{array}{l}\text { IFN } \gamma \text {-expressing CD8+ and IFN } \gamma \text {-expressing } \\
\text { CD4+ T cells } \uparrow P D-L 1 \text { expression on relapsing } \\
\text { tumor cells } \uparrow \text { Vessel normalization } \uparrow \text { by PD-L1 } \\
\text { blockade and formation of HEVs } \uparrow\end{array}$ & $(179)$ \\
\hline Anti-PD-L1 antibody & $\begin{array}{l}\text { CVX-060 (ANG2-specific peptide-antibody fusion } \\
\text { protein) } \pm \text { sunitinib or regorafenib (both VEFGR } \\
\text { TKIs) or CVX-241 (bi-specific ANG2-VEGF-binding } \\
\text { peptide-antibody fusion protein) }\end{array}$ & $\begin{array}{l}\text { Breast cancer, } \\
\text { Colorectal cancer, } \\
\text { Renal cancer }\end{array}$ & $\begin{array}{l}\text { Tumor growth and metastatic progression } \downarrow \\
\text { with combined inhibition of ANG2 and VEGF } \\
\text { signalling (with or without immune-checkpoint } \\
\text { blockade) }\end{array}$ & (196) \\
\hline Anti-mouse CTLA-4 antibody & Axitinib (Anti-VEGFR) & Melanoma & Effector $\uparrow$ cell $\uparrow$ Animal Survival $\uparrow$ & (199) \\
\hline Anti-PD-L1 antibody & Anti-VEGF & $\begin{array}{l}\text { Small-cell lung } \\
\text { cancer (SCLC) }\end{array}$ & Animal Survival $\uparrow C D 4+T$-cell infiltration $\uparrow$ & (200) \\
\hline
\end{tabular}

using a TNF-RGR peptide, which increased vessel stabilization, vessel perfusion and enhanced $\mathrm{T}$ cell infiltration, hereby improving overall survival after antitumor vaccination or adoptive T-cell therapy (229). Similar results were obtained with a NGR-TNF peptide (230). Another method involves immunocytokines, of which the target molecules are often angiogenesis related molecules in solid cancers, including EDA and EDB domains of fibronectin and the extra-domain A1 of tenascin-C. These molecules are specifically expressed in angiogenic parts of tumor vasculature but not detectable in normal tissues (231). F8, L19 and F16 antibodies are specific to the EDA, EDB, and A1 domain, respectively $(232,233)$. As such, these antibodies are ideal to generate cytokine-fusion antibodies targeting tumor associated vasculature.

L19-IL2 is a well described immunocytokine having a central role in the regulation of $\mathrm{T}$ cell responses and effects on other immune cells, such as natural killer cells, B cells, monocytes, macrophages and neutrophils. IL2 can induce tumor regression through its ability to stimulate a potent cell-mediated immune response in vivo $(234,235)$. L19-IL2 as well as L19TNF are now being evaluated in phase II clinical trials through intratumoral application in stage III or IV melanoma patients (236).

Targeting tumor vasculature with anti-angiogenesis agents or immunocytokines increases leukocyte trafficking through upregulation of CAM expression on cancer endothelium. As such, blocking key adhesion receptors involved in leukocyte transendothelial migration might be an effective approach to modulate selective trafficking of leukocytes (Figure 8D). Although generic CAMs can bind integrins expressed by several leukocyte subtypes, blocking specific CAMs might govern selective migration across tumor vessels. For instance, blocking antibodies targeting Clever-1 or ETBR, which are key surface molecules involved in Treg cell transmigration across tumor vasculature, impaired Treg cell but not CD8+ T cell entry into tumors $(10,103,108)$. 
TABLE 2 | Clinical studies on combinations of antiangiogenic agents and immunotherapies.

\begin{tabular}{|c|c|c|c|c|}
\hline Immunotherapy & Antiangiogenic therapy & Disease & Status & $\begin{array}{l}\text { ClinicalTrials.gov } \\
\text { identifier } \\
\text { (publication) }\end{array}$ \\
\hline \multicolumn{5}{|l|}{ Vaccination Studies } \\
\hline PF 06755990 (vaccine) & Sunitinib (TKI) & Prostate cancer & Phase l: & NCT02616185 \\
\hline $\begin{array}{l}\text { Pox virus vaccine (expressing } \\
\text { GM CSF) }\end{array}$ & Sorafenib (TKI) & $\mathrm{HCC}$ & Phase III: & NCT02562755 \\
\hline \multicolumn{5}{|c|}{ Immunostimulatory Cytokine Studies } \\
\hline IFN $\alpha$ & Bevacizumab (anti-VEGF) & Metastatic RCC & Phase III (CALGB 90206): completed & NA (207) \\
\hline IFNo2A & Bevacizumab (anti-VEGF) & Metastatic RCC & Phase III (AVOREN): completed & NA (208) \\
\hline \multicolumn{5}{|l|}{ Cell Therapy Studies } \\
\hline NK cell-based immunotherapy & Bevacizumab (anti-VEGF) & Advanced-stage solid tumors & Phase I/II: completed & NCT02857920 \\
\hline Autologous DC immunotherapy & Sunitinib (TKI) & Advanced-stage RCC & Phase II: completed & $\begin{array}{l}\text { NCT00678119 } \\
\text { (209) }\end{array}$ \\
\hline \multicolumn{5}{|c|}{ Immune-Checkpoint Blockade Studies } \\
\hline Ipilimumab (anti-CTLA-4) & Bevacizumab (anti-VEGF) & Advanced-stage melanoma & Phase I: completed & NA (210) \\
\hline $\begin{array}{l}\text { Ipilimumab (anti-CTLA-4) or } \\
\text { Nivolumab (anti-PD-1) }\end{array}$ & Bevacizumab (anti-VEGF) & Metastatic melanoma & Phase NA: completed & NA (201) \\
\hline Ipilimumab (anti-CTLA-4) & Bevacizumab (anti-VEGF) & Metastatic RCC & Phase l: & NCT02210117 \\
\hline Ipilimumab (anti-CTLA-4) & Bevacizumab (anti-VEGF) & Melanoma & Phase II: & NCT01950390 \\
\hline Ipilimumab (anti-CTLA-4) & Bevacizumab (anti-VEGF) & Melanoma & Phase I: & NCT00790010 \\
\hline Nivolumab (anti-PD-1) & Bevacizumab (anti-VEGF) & NSCLC & Phase I: (safety and tolerability, ORR, and RFS) & NCT01454102 \\
\hline Nivolumab (anti-PD-1) & Sunitinib or pazopanib (TKI) & Metastatic RCC & Phase l: & $\begin{array}{l}\text { NCT01472081 } \\
(211)\end{array}$ \\
\hline Pembrolizumab (anti-PD-1) & Axitinib (TKI) & $\mathrm{RCC}$ & Phase III: & NCT02853331 \\
\hline Pembrolizumab (anti-PD-1) & $\begin{array}{l}\text { Nintedanib (broad TKI and } \\
\text { nTKI) }\end{array}$ & Advanced-stage solid tumors & Phase I: & NCT02856425 \\
\hline Pembrolizumab (anti-PD-1) & Bevacizumab (anti-VEGF) & Glioblastoma & Phase II: completed & NCT02337491 \\
\hline Pembrolizumab (anti-PD-1) & Ramucirumab (anti-VEGFR2) & $\begin{array}{l}\text { Gastric or gastro-oesophageal } \\
\text { adenocarcinoma, NSCLC, } \\
\text { urothelial carcinoma, or biliary } \\
\text { tract cancer }\end{array}$ & Phase I: completed & $\begin{array}{l}\text { NCT02443324 } \\
(212)\end{array}$ \\
\hline Atezolizumab (anti-PD-L1) & Bevacizumab (anti-VEGF) & Non-clear-cell RCC & Phase II: & $\begin{array}{l}\text { NCT02724878 } \\
(213)\end{array}$ \\
\hline Atezolizumab (anti-PD-L1) & Bevacizumab (anti-VEGF) & Metastatic cervical cancer & Phase II: & NCT02921269 \\
\hline Atezolizumab (anti-PD-L1) & Bevacizumab (anti-VEGF) & Multiple solid tumors & Phase I: & $\begin{array}{l}\text { NCT01633970 } \\
(214)\end{array}$ \\
\hline Atezolizumab (anti-PD-L1) & Bevacizumab (anti-VEGF) & Non-Small-Cell Lung Cancer & Phase III: & $\begin{array}{l}\text { NCT02366143 } \\
(215,216)\end{array}$ \\
\hline Atezolizumab (anti-PD-L1) & $\begin{array}{l}\text { Vanucizumab (bi-specific } \\
\text { mAb targeting VEGF and } \\
\text { ANG2) }\end{array}$ & Advanced-stage solid tumors & Phase I: completed (MTD, AEs, and ORR) & NCT01688206 \\
\hline Avelumab (anti-PD-L1) & Axitinib (TKI) & Advanced-stage RCC & Phase I: & $\begin{array}{l}\text { NCT02493751 } \\
(217)\end{array}$ \\
\hline Avelumab (anti-PD-L1) & Axitinib (TKI) & Advanced-stage RCC & Phase III: & $\begin{array}{l}\text { NCT02684006 } \\
(218,219)\end{array}$ \\
\hline $\begin{array}{l}\text { Selicrelumab (RO7009789- } \\
\text { agonistic anti-CD40 mAb) }\end{array}$ & $\begin{array}{l}\text { Vanucizumab (bi-specific } \\
\text { mAb targeting VEGF and } \\
\text { ANG2) }\end{array}$ & Metastatic solid tumors & $\begin{array}{l}\text { Phase I: completed (safety, pharmacokinetics } \\
\text { and pharmacodynamics, and therapeutic } \\
\text { activity) }\end{array}$ & NCT02665416 \\
\hline Durvalumab (anti-PD-L1) & Ramucirumab (anti-VEGFR2) & $\begin{array}{l}\text { Gastric or gastro-oesophageal } \\
\text { adenocarcinoma, NSCLC or } \\
\text { HCC }\end{array}$ & Phase I: & NCT02572687 \\
\hline SHR-1210 (anti-PD-1 mAb) & Apatinib (TKI, VEGFR2) & Gastric cancer and HCC & $\begin{array}{l}\text { Phase I/II: (tumor control rate, disease control } \\
\text { rate, OS, and AEs) }\end{array}$ & $\begin{array}{l}\text { NCT02942329 } \\
(220)\end{array}$ \\
\hline
\end{tabular}

Another approach to modulate selectivity through endothelial CAM expression is targeting the co-stimulatory molecule CD137 (4-1BB), which is selectively expressed on the surface of tumor endothelial cells, and induced by hypoxia. Agonistic antibodies targeting CD137 increase E-selectin, ICAM-1, and VCAM-1 surface expression on tumor vessels. This restoration of CAM expression increased $\mathrm{T}$ cell trafficking across tumor blood vessels improving infiltration of $\mathrm{T}$ lymphocytes into malignant tissue (237) (Figure 8E).

Finally, selective trafficking of leukocytes might be modulated through interfering with chemokine signals. Such an approach may involve targeted delivery of siRNAs that locally interferes with chemokine signaling affecting the selective trafficking of certain leukocytes into the TME (Figure 8F). Several lines of data show the 
feasibility of this approach. For instance, in vivo nanoparticle delivery of siCX3CL1 inhibited non classical Ly6 $\mathrm{C}^{\text {lo }}$ monocyte infiltration and enhanced efficacy of anti-VEGFR2 therapy (154). Additionally, intelligent nanorobots have been described that are able to deliver anticancer therapeutics to tumor vessels, targeting tumor endothelial specific nucleolin (238). In this case thrombin was locally delivered to induce rapid shutdown of tumor vasculature, which induced necrosis and inhibition of tumor growth. Similar nanorobots may also deliver cytokines and/or anti-angiogenesis agents locally to tumors to redirect selective trafficking of leukocytes and to modulate the tumor microenvironment.

\section{CONCLUDING REMARKS AND FUTURE DIRECTIONS}

In conclusion, vascular normalization with anti-angiogenic agents may counteract immunosuppression and increase leukocyte entry into tumors, hereby opening a window of opportunity to combine anti-angiogenic agents with immunotherapy. Understanding the regulation of selective immune cell trafficking may establish better approaches that govern selective immune cell infiltration in cancer to make better use of the therapeutic window during vascularization normalization. So far, the majority of research is focused on increasing the infiltration of cytotoxic immune cells in tumors.

\section{REFERENCES}

1. Chapman PB, D'Angelo SP, Wolchok JD. Rapid eradication of a bulky melanoma mass with one dose of immunotherapy. N Engl J Med (2015) 372:2073-4. doi: 10.1056/NEJMc1501894

2. Robert C, Schachter J, Long GV, Arance A, Grob JJ, Mortier L, et al. Pembrolizumab versus Ipilimumab in Advanced Melanoma. $N$ Engl J Med (2015) 372:2521-32. doi: 10.1056/NEJMoa1503093

3. Dammeijer F, Lau SP, van Eijck CHJ, van der Burg SH, Aerts JGJV. Rationally combining immunotherapies to improve efficacy of immune checkpoint blockade in solid tumors. Cytokine Growth Factor Rev (2017) 36:5-15. doi: 10.1016/j.cytogfr.2017.06.011

4. Chen DS, Mellman I. Elements of cancer immunity and the cancer-immune set point. Nature (2017) 541:321-30. doi: 10.1038/nature21349

5. Hegde PS, Karanikas V, Evers S. The where, the when, and the how of immune monitoring for cancer immunotherapies in the era of checkpoint inhibition. Clin Cancer Res (2016) 22:1865-74. doi: 10.1158/10780432.CCR-15-1507

6. Galon J, Bruni D. Approaches to treat immune hot, altered and cold tumours with combination immunotherapies. Nat Rev Drug Discovery (2019) 18:197-218. doi: 10.1038/s41573-018-0007-y

7. Joyce JA, Fearon DT. T cell exclusion, immune privilege, and the tumor microenvironment. Cancer Immunol Immunother (2015) 348:74-80. doi: 10.1017/CBO9781107415324.004

8. Pai SI, Cesano A, Marincola FM. The Paradox of Cancer Immune Exclusion: Immune Oncology Next Frontier. Cancer Treat Res (2020) 180:173-95. doi: 10.1016/j.physbeh.2017.03.040

9. Voron T, Colussi O, Marcheteau E, Pernot S, Nizard M, Pointet AL, et al. VEGF-A modulates expression of inhibitory checkpoints on CD8+ T cells in tumors. J Exp Med (2015) 212:139-48. doi: 10.1084/jem.20140559

10. Buckanovich RJ, Facciabene A, Kim S, Benencia F, Sasaroli D, Balint K, et al. Endothelin B receptor mediates the endothelial barrier to $\mathrm{T}$ cell homing to
However, the selective inhibition of immunosuppressive immune cells might be equally important, as these cells modulate the activity of cytotoxic immune cells after they have entered the TME. Thus, molecules involved in selective trafficking might provide novel predictive markers to provide a rational for combining vascular targeting agents with specific immunotherapy strategies. Ultimately, improving immunotherapy through vascular normalization may lead to significantly better clinical outcome of many cancer patients.

\section{AUTHOR CONTRIBUTIONS}

GD, ME, and $\mathrm{NH}$ co-wrote the manuscript. NH prepared the figures. All authors contributed to the article and approved the submitted version.

\section{FUNDING}

$\mathrm{NH}$ is supported by the Dutch Cancer Society grant 12863 and Cancer Center Amsterdam grant CCA2017-5-39. ME is supported by the Dutch Cancer Society grant 12749 . GD is supported by the Program of Selection and Placement of Students for Overseas Postgraduate Education (YLSY) scholarship, awarded by the Turkish Ministry of National Education. tumors and disables immune therapy. Nat Med (2008) 14:28-36. doi: $10.1038 / \mathrm{nm} 1699$

11. Motz GT, Santoro SP, Wang LP, Garrabrant T, Lastra RR, Hagemann IS, et al. Tumor endothelium FasL establishes a selective immune barrier promoting tolerance in tumors. Nat Med (2014) 20:607-15. doi: 10.1038/nm.3541

12. Pivarcsi A, Müller A, Hippe A, Rieker J, Van Lierop A, Steinhoff M, et al. Tumor immune escape by the loss of homeostatic chemokine expression. Proc Natl Acad Sci USA (2007) 104:19055-60. doi: 10.1073/pnas.0705673104

13. Molon B, Ugel S, Del Pozzo F, Soldani C, Zilio S, Avella D, et al. Chemokine nitration prevents intratumoral infiltration of antigen-specific T cells. J Exp Med (2011) 208:1949-62. doi: 10.1084/jem.20101956

14. Kather JN, Suarez-Carmona M, Charoentong P, Weis CA, Hirsch D, Bankhead P, et al. Topography of cancer-associated immune cells in human solid tumors. Elife (2018) 7:1-19. doi: 10.7554/eLife.36967

15. Fukumura D, Kloepper J, Amoozgar Z, Duda DG, Jain RK. Enhancing cancer immunotherapy using antiangiogenics: Opportunities and challenges. Nat Rev Clin Oncol (2018) 15:325-40. doi: 10.1038/nrclinonc.2018.29

16. Ramjiawan R, Griffioen AW, Duda DG. Anti-angiogenesis for cancer revisited: Is there a role for combinations with immunotherapy? Angiogenesis (2017) 20:185-204. doi: 10.1016/j.physbeh.2017.03.040

17. Khan KA, Kerbel RS. Improving immunotherapy outcomes. Nat Rev Clin Oncol (2018) 15:310-24. doi: 10.1038/nrclinonc.2018.9

18. Huang Y, Kim BYS, Chan CK, Hahn SM, Weissman IL, Jiang W. Improving immune-vascular crosstalk for cancer immunotherapy. Cancer Immunother Perspect (2018) 18:195-203. doi: 10.1038/nri.2017.145

19. Jain RK. Antiangiogenesis strategies revisited: from starving Ttumors to alleviating hypoxia. Cancer Cell (2014) 26:605-22. doi: 10.1016/ j.ccell.2014.10.006.ANTIANGIOGENESIS

20. Noman MZ, Desantis G, Janji B, Hasmim M, Karray S, Dessen P, et al. PDL1 is a novel direct target of HIF- $1 \alpha$, and its blockade under hypoxia enhanced: MDSC-mediated T cell activation. J Exp Med (2014) 211:781-90. doi: $10.1084 /$ jem.20131916 
21. Corzo CA, Condamine T, Lu L, Cotter MJ, Youn J, Cheng P, et al. HIF-1 $\alpha$ regulates function and differentiation of myeloid-derived suppressor cells in the tumor microenvironment. J Exp Med (2010) 207:2439-53. doi: 10.1084/ jem.20100587

22. Doedens AL, Stockmann C, Rubinstein MP, Liao D, Denardo DG, Coussens LM, et al. Macrophage Expression of HIF-1 $\alpha$ Suppresses T cell Function and Promotes Tumor Progression. Cancer Lett (2010) 70:7465-75. doi: 10.1158/ 0008-5472.CAN-10-1439.Macrophage

23. Facciabene A, Peng X, Hagemann IS, Balint K, Barchetti A, Wang LP, et al. Tumour hypoxia promotes tolerance and angiogenesis via CCL28 and T reg cells. Nature (2011) 475:226-30. doi: 10.1038/nature10169

24. Colegio OR, Chu NQ, Szabo AL, Chu T, Rhebergen AM, Jairam V, et al. Functional polarization of tumour-associated macrophages by tumourderived lactic acid. Nature (2014) 513:559-63. doi: 10.1038/nature13490

25. Curiel TJ, Coukos G, Zou L, Alvarez X, Cheng P, Mottram P, et al. Specific recruitment of regulatory $\mathrm{T}$ cells in ovarian carcinoma fosters immune privilege and predicts reduced survival. Nat Med (2004) 10:942-9. doi: $10.1038 / \mathrm{nm} 1093$

26. Rodig N, Ryan T, Allen JA, Pang H, Grabie N, Chernova T, et al. Endothelial expression of PD-L1 and PD-L2 down-regulates CD8+ T cell activation and cytolysis. Eur J Immunol (2003) 33:3117-26. doi: 10.1002/eji.200324270

27. Shetty S, Weston CJ, Oo YH, Westerlund N, Stamataki Z, Youster J, et al. Common Lymphatic Endothelial and Vascular Endothelial Receptor-1 Mediates the Transmigration of Regulatory T Cells across Human Hepatic Sinusoidal Endothelium. J Immunol (2011) 186:4147-55. doi: 10.4049/ jimmunol.1002961

28. Nakashima S, Sugita Y, Miyoshi H, Arakawa F, Muta H, Ishibashi Y, et al. Endothelin B receptor expression in malignant gliomas: the perivascular immune escape mechanism of gliomas. J Neurooncol (2016) 127:23-32. doi: 10.1007/s11060-015-2017-5

29. Nummer D, Suri-Payer E, Schmitz-Winnenthal H, Bonertz A, Galindo L, Antolovich D, et al. Role of tumor endothelium in $\mathrm{CD} 4+\mathrm{CD} 25+$ regulatory $\mathrm{T}$ cell infiltration of human pancreatic carcinoma. J Natl Cancer Inst (2007) 99:1188-99. doi: 10.1093/jnci/djm064

30. Quezada SA, Peggs KS, Simpson TR, Shen Y, Littman DR, Allison JP. Limited tumor infiltration by activated $\mathrm{T}$ effector cells restricts the therapeutic activity of regulatory $\mathrm{T}$ cell depletion against established melanoma. J Exp Med (2008) 205:2125-38. doi: 10.1084/jem.20080099

31. Bose A, Taylor JL, Alber S, Watkins SC, Garcia JA, Rini BI, et al. Immunity in Concert With Specific Vaccination. Int J Cancer (2011) 129:2158-70. doi: 10.1002/ijc.25863.Sunitinib

32. Huang Y, Yuan J, Righi E, Kamoun WS, Ancukiewicz M, Nezivar J, et al. Vascular normalizing doses of antiangiogenic treatment reprogram the immunosuppressive tumor microenvironment and enhance immunotherapy. Proc Natl Acad Sci USA (2012) 109:17561-6. doi: 10.1073/pnas.1215397109

33. Manning EA, Ullman JGM, Leatherman JM, Asquith JM, Hansen TR, Armstrong TD, et al. A vascular endothelial growth factor receptor-2 inhibitor enhances antitumor immunity through an immune-based mechanism. Clin Cancer Res (2007) 13:3951-9. doi: 10.1158/1078-0432.CCR-07-0374

34. Shrimali RK, Yu Z, Theoret MR, Chinnasamy D, Restifo NP, Rosenberg SA. Antiangiogenic Agents Can Increase Lymphocyte Infiltration into Tumor and Enhance the Effectiveness of Adoptive Immunotherapy of Cancer. Cancer Res (2010) 70:6171-80. doi: 10.1158/0008-5472.CAN-10-0153

35. Kloepper J, Riedemann L, Amoozgar Z, Seano G, Susek K, Yu V, et al. Ang2/VEGF bispecific antibody reprograms macrophages and resident microglia to anti-tumor phenotype and prolongs glioblastoma survival. Proc Natl Acad Sci USA (2016) 113:4476-81. doi: 10.1073/pnas.1525360113

36. Park JS, Kim IK, Han S, Park I, Kim C, Bae J, et al. Normalization of Tumor Vessels by Tie2 Activation and Ang2 Inhibition Enhances Drug Delivery and Produces a Favorable Tumor Microenvironment. Cancer Cell (2016) 30:95367. doi: 10.1016/j.ccell.2016.10.018

37. Martin JD, Cabral H, Stylianopoulos T, Jain RK. Improving cancer immunotherapy using nanomedicines: progress, opportunities and challenges. Nat Rev Clin Oncol (2020) 17:251-66. doi: 10.1038/s41571019-0308-z

38. Sherwood LM, Parris EE, Folkman J. Tumor Angiogenesis: Therapeutic Implications. N Engl J Med (1971) 285:1182-6. doi: 10.1056/ NEJM197111182852108
39. Baeriswyl V, Christofori G. Seminars in Cancer Biology The angiogenic switch in carcinogenesis. Semin Cancer Biol (2009) 19:329-37. doi: 10.1016/ j.semcancer.2009.05.003

40. Folkman J. Fundamental Concepts of the Angiogenic Process. Curr Mol Med (2003) 3:643-51. doi: 10.2174/1566524033479465

41. Mousa SA, Rajabi M. The role of angiogenesis in cancer treatment. Biomedicines (2017) 5:1-12. doi: 10.3390/biomedicines5020034

42. Relf M, Lejeune S, Scott PAE, Fox S, Smith K, Leek R, et al. Expression of the angiogenic factors vascular endothelial cell growth factor, acidic and basic fibroblast growth factor, tumor growth factor beta-1, platelet-derived endothelial cell growth factor, placenta growth factor, and pleiotrophin in human primary breast cancer and its relation to angiogenesis. Cancer Res (1997) 57:963-9.

43. Rak J, Klement G. Impact of oncogenes and tumor suppressor genes on deregulation of hemostasis and angiogenesis in cancer. Cancer Metastasis Rev (2000) 19:93-6. doi: 10.1023/a:1026516920119

44. Dvorak HF. Tumors:Wounds That Do Not Heal. N Engl J Med (1986) 315:1650-9. doi: 10.1056/NEJM198612253152606

45. Foster DS, Longaker MT, Jeffrey A, Foster DS, Jones RE, Ransom RC, et al. The evolving relationship of wound healing and tumor stroma Find the latest version : The evolving relationship of wound healing and tumor stroma. J Clin Invest (2018) 3:1-17. doi: 10.1172/jci.insight.99911

46. Fisher DT, Muhitch JB, Kim M, Doyen KC, Bogner PN, Evans SS, et al. Intraoperative intravital microscopy permits the study of human tumour vessels. Nat Commun (2016) 7:1-9. doi: 10.1038/ncomms10684

47. Heikal L, Ferns GAA. Hypoxia, angiogenesis and atherogenesis. In: Physiologic and Pathologic Angiogenesis - Signaling Mechanisms and Targeted Therapy. IntechOpen (2017).

48. Gabrilovich DI, Chen HL, Girgis KR, Cunningham HT, Meny GM, Nadaf S, et al. Production of vascular endothelial growth factor by human tumors inhibits the functional maturation of dendritic cells. Nat Med (1996) 2:1096103. doi: $10.1038 / \mathrm{nm} 1096-1096$

49. Ohm JE, Gabrilovich DI, Sempowski GD, Kisseleva E, Parman KS, Nadaf S, et al. VEGF inhibits T-cell development and may contribute to tumorinduced immune suppression. Blood (2003) 101:4878-86. doi: 10.1182/ blood-2002-07-1956

50. Casazza A, Di Conza G, Wenes M, Finisguerra V, Deschoemaeker S, Mazzone M. Tumor stroma: A complexity dictated by the hypoxic tumor microenvironment. Oncogene (2014) 33:1743-54. doi: 10.1038/onc.2013.121

51. Sidibe A, Ropraz P, Jemelin S, Emre Y, Poittevin M, Pocard M, et al. Angiogenic factor-driven inflammation promotes extravasation of human proangiogenic monocytes to tumours. Nat Commun (2018) 9(1):355. doi: 10.1038/s41467-017-02610-0

52. Jung K, Heishi T, Incio J, Huang Y, Beech EY, Pinter M, et al. Targeting CXCR4-dependent immunosuppressive Ly6Clow monocytes improves antiangiogenic therapy in colorectal cancer. Proc Natl Acad Sci USA (2017) 114:10455-60. doi: 10.1073/pnas.1710754114

53. Imtiyaz HZ, Williams EP, Hickey MM, Patel SA, Durham AC, Yuan L, et al. Hypoxia-inducible factor $2 \alpha$ regulates macrophage function in mouse models of acute and tumor inflammation. J Clin Invest (2010) 120:2699714. doi: 10.1172/JCI39506.phages

54. Clambey ET, Mcnamee EN, Westrich JA, Glover LE, Campbell EL, Jedlicka P. Hypoxia-inducible factor-1 alpha - dependent induction of FoxP3 drives regulatory T-cell abundance and function during in $\mathrm{fl}$ ammatory hypoxia of the mucosa. Proc Natl Acad Sci USA (2012) 109:2784-93. doi: 10.1073/ pnas. 1202366109

55. Rytelewski M, Haryutyunan K, Nwajei F, Shanmugasundaram M, Wspanialy $\mathrm{P}, \mathrm{Zal} \mathrm{MA}$, et al. Merger of dynamic two-photon and phosphorescence lifetime microscopy reveals dependence of lymphocyte motility on oxygen in solid and hematological tumors. J Immunother Cancer (2019) 7:1-13. doi: 10.1186/s40425-019-0543-y

56. Heemskerk N, Van Rijssel J, Van Buul JD. Rho-GTPase signaling in leukocyte extravasation: An endothelial point of view. Cell Adhes Migr (2014) 8:67-75. doi: 10.4161/cam.28244

57. Heemskerk N, Schimmel L, Oort C, van Rijssel J, Yin T, Ma B, et al. F-actinrich contractile endothelial pores prevent vascular leakage during leukocyte diapedesis through local RhoA signalling. Nat Commun (2016) 7:10493. doi: $10.1038 /$ ncomms 10493 
58. Butcher EC. Leukocyte-Endothelial Cell Recognition: Three (or More) Steps to Specificity and Diversity Minireview. Cell (1991) 67:1033-6. doi: 10.1016/ 0092-8674(91)90279-8

59. Springer TA. Traffic signals for lymphocyte recirculation and leukocyte emigration: The multistep paradigm. Cell (1994) 76:301-14. doi: 10.1016/ 0092-8674(94)90337-9

60. Schimmel L, Heemskerk N, van Buul JD. Leukocyte transendothelial migration: A local affair. Small GTPases (2017) 8:1-15. doi: 10.1080/ 21541248.2016.1197872

61. Borsig L. Selectins in cancer immunity. Glycobiology (2018) 28:648-55. doi: $10.1093 / \mathrm{glycob} / \mathrm{cwx} 105$.Selectins

62. Hobbs SJ, Nolz JC. Regulation of T cell trafficking by enzymatic synthesis of O-glycans. Front Immunol (2017) 8:600. doi: 10.3389/fimmu.2017.00600

63. Wang L, Fuster M, Sriramarao P, Esko JD. Endothelial heparan sulfate deficiency impairs L-selectin- and chemokine-mediated neutrophil trafficking during inflammatory responses. Nat Immunol (2005) 6:902-10. doi: $10.1038 /$ ni1233

64. Parish CR. The role of heparan sulphate in inflammation. Nat Rev Immunol (2006) 6:633-43. doi: 10.1038/nri1918

65. Martinelli R, Zeiger AS, Whitfield M, Sciuto TE, Dvorak A, Van Vliet KJ, et al. Probing the biomechanical contribution of the endothelium to lymphocyte migration: diapedesis by the path of least resistance. J Cell Sci (2014) 127:3720-34. doi: 10.1242/jcs.148619

66. Renkawitz J, Kopf A, Stopp J, de Vries I, Driscoll MK, Merrin J, et al. Nuclear positioning facilitates amoeboid migration along the path of least resistance. Nature (2019) 568:546-50. doi: 10.1038/s41586-019-1087-5

67. Akino T, Hida K, Hida Y, Tsuchiya K, Freedman D, Muraki C, et al. Cytogenetic abnormalities of tumor-associated endothelial cells in human malignant tumors. Am J Pathol (2009) 175:2657-67. doi: 10.2353/ ajpath.2009.090202

68. Hida K, Hida Y, Amin DN, Flint AF, Panigrahy D, Morton CC, et al. Tumorassociated endothelial cells with cytogenetic abnormalities. Cancer Res (2004) 64:8249-55. doi: 10.1158/0008-5472.CAN-04-1567

69. Seaman S, Stevens J, Yang MY, Logsdon D, Graff-Cherry C, Croix BS. Genes that Distinguish Physiological and Pathological Angiogenesis. Cancer Cell (2007) 11:539-54 13(2):R47. doi: 10.1016/j.ccr.2007.04.017

70. Lu C, Bonome T, Li Y, Kamat AA, Han LY, Schmandt R, et al. Gene alterations identified by expression profiling in tumor-associated endothelial cells from invasive ovarian carcinoma. Cancer Res (2007) 67:1757-68. doi: 10.1158/0008-5472.CAN-06-3700

71. Lambrechts D, Wauters E, Boeckx B, Aibar S, Nittner D, Burton O, et al. Phenotype molding of stromal cells in the lung tumor microenvironment. Nat Med (2018) 24:1277-89. doi: 10.1038/s41591-018-0096-5

72. Goveia J, Rohlenova K, Taverna F, Treps L, Conradi LC, Pircher A, et al. An Integrated Gene Expression Landscape Profiling Approach to Identify Lung Tumor Endothelial Cell Heterogeneity and Angiogenic Candidates. Cancer Cell (2020) 37:21-36.e13. doi: 10.1016/j.ccell.2019.12.001

73. Kuczynski EA, Vermeulen PB, Pezzella F, Kerbel RS, Reynolds AR. Vessel co-option in cancer. Nat Rev Clin Oncol (2019) 16:469-93. doi: 10.1038/ s41571-019-0181-9

74. Dudley AC. Tumor endothelial cells. Cold Spring Harb Perspect Med (2012) 2:1-18. doi: 10.1101/cshperspect.a006536

75. Langenkamp E, vom Hagen FM, Zwiers PJ, Moorlag HE, Schouten JP, Hammes H-P, et al. Tumor Vascular Morphology Undergoes Dramatic Changes during Outgrowth of B16 Melanoma While Proangiogenic Gene Expression Remains Unchanged. ISRN Oncol (2011) 2011:1-14. doi: $10.5402 / 2011 / 409308$

76. Griffioen AW, Damen CA, Blijham GH, Groenewegen G. Tumor angiogenesis is accompanied by a decreased inflammatory response of tumor-associated endothelium. Blood (1996) 88:667-73. doi: 10.1182/ blood.v88.2.667.bloodjournal882667

77. Griffioen AW, Damen CA, Martinotti S, Blijham GH, Groenewegen G. Endothelial intercellular adhesion molecule-1 expression is suppressed in human malignancies: The role of angiogenic factors. Cancer Res (1996) 56:1111-7.

78. Boissonnas A, Fetler L, Zeelenberg IS, Hugues S, Amigorena S. In vivo imaging of cytotoxic $\mathrm{T}$ cell infiltration and elimination of a solid tumor. J Exp Med (2007) 204:345-56. doi: 10.1084/jem.20061890
79. Barthel SR, Gavino JD, Descheny L, Dimitroff CJ. Targeting selectins and selectin ligands in inflammation and cancer. Expert Opin Ther Targets (2007) 11:1473-91. doi: 10.1517/14728222.11.11.1473.Targeting

80. Harlin H, Meng Y, Peterson AC, Zha Y, Tretiakova M, Slingluff C, et al. Chemokine Expression in Melanoma Metastases Associated with CD8+ TCell Recruitment. Cancer Res (2009) 69:1-18. doi: 10.1158/0008-5472.CAN08-2281.Chemokine

81. Musha H, Ohtani H, Mizoi T, Kinouchi M, Nakayama T, Shiiba K. Selective infiltration of CCR5 1 CXCR3 $1 \mathrm{~T}$ lymphocytes in human colorectal carcinoma. Int J Cancer (2005) 956:949-56. doi: 10.1002/ijc.21135

82. Mulligan AM, Raitman I, Feeley L, Pinnaduwage D, Nguyen LT, O’Malley FP, et al. Tumoral lymphocytic infiltration and expression of the chemokine CXCL10 in breast cancers from the ontario familial breast cancer registry. Clin Cancer Res (2013) 19:336-46. doi: 10.1158/10780432.CCR-11-3314

83. Kunz M, Toksoy A, Goebeler M, Engelhardt E, Bröcker EB, Gillitzer R. Strong expression of the lymphoattractant $\mathrm{C}-\mathrm{X}-\mathrm{C}$ chemokine Mig is associated with heavy infiltration of $\mathrm{T}$ cells in human malignant melanoma. J Pathol (1999) 189:552-8. doi: 10.1002/(SICI)1096-9896 (199912)189:4<552::AID-PATH469>3.0.CO;2-I

84. Mullins IM, Slingluff CL, Lee JK, Garbee CF, Shu J, Anderson SG, et al. CXC chemokine receptor 3 expression by activated CD8+ T cells is associated with survival in melanoma patients with stage III disease. Cancer Res (2004) 64:7697-701. doi: 10.1158/0008-5472.CAN-04-2059

85. Guirnalda P, Wood L, Goenka R, Crespo J, Paterson Y. Interferon $\gamma$-induced intratumoral expression of CXCL9 alters the local distribution of T cells following immunotherapy with Listeria monocytogenes. Oncoimmunology (2013) 2:1-9. doi: 10.4161/onci.25752

86. Tannenbaum CS, Tubbs R, Armstrong D, Finke JH, Bukowski RM, Hamilton TA. The CXC chemokines IP-10 and Mig are necessary for IL12-mediated regression of the mouse RENCA tumor. J Immunol (1998) 161:927-32.

87. Moon EK, Carpenito C, Sun J, Wang LCS, Kapoor V, Predina J, et al. Expression of a functional CCR2 receptor enhances tumor localization and tumor eradication by retargeted human $\mathrm{T}$ cells expressing a mesothelinspecific chimeric antibody receptor. Clin Cancer Res (2011) 17:4719-30. doi: 10.1158/1078-0432.CCR-11-0351

88. Fukumura D, Salehi HA, Witwer B, Melder RJ, Jain RK, Tuma RF. Tumor Necrosis Factor $\alpha$-induced Leukocyte Adhesion in Normal and Tumor Vessels: Effect of Tumor Type, Transplantation Site, and Host Strain. Cancer Res (1995) 55:4824-9.

89. Colombo MP, Lombardi L, Melani C, Parenza M, Baroni C, Ruco L, et al. Hypoxic Tumor Cell Death and Modulation of Endothelial Adhesion Molecules in the Regression of Granulocyte Colony-Stimulating. Am J Pathol (1996) 148:473-83.

90. Griffin GK, Newton G, Tarrio ML, Bu D, Maganto-Garcia E, Azcutia V, et al. IL-17 and TNF- $\alpha$ Sustain Neutrophil Recruitment during Inflammation through Synergistic Effects on Endothelial Activation. J Immunol (2012) 188:6287-99. doi: 10.4049/jimmunol.1200385

91. Groom JR, Luster AD. CXCR3 ligands: redundant, collaborative and antagonistic functions. Immunol Cell Biol (2011) 89:207-15. doi: 10.1038/ icb.2010.158.CXCR3

92. Ogawa M, Tsutsui T, Zou J-P, Mu J, Wijesuriya R, Yu W-G, et al. Enhanced Induction of Very Late Antigen 4 / Lymphocyte Function-associated Antigen 1-dependent T-Cell Migration to Tumor Sites following Administration of Interleukin 12. Cancer Res (1997) 57:2216-22.

93. Fisher DT, Chen Q, Skitzki JJ, Muhitch JB, Zhou L, Appenheimer MM, et al. IL-6 trans-signaling licenses mouse and human tumor microvascular gateways for trafficking of cytotoxic T cells. J Clin Invest (2011) 121:384659. doi: 10.1172/JCI44952

94. Garbi N, Arnold B, Gordon S, Hämmerling GJ, Ganss R. CpG Motifs as Proinflammatory Factors Render Autochthonous Tumors Permissive for Infiltration and Destruction. J Immunol (2004) 172:5861-9. doi: 10.4049/ jimmunol.172.10.5861

95. Lohr J, Ratliff T, Huppertz A, Ge Y, Dictus C, Ahmadi R, et al. Effector T-cell infiltration positively impacts survival of glioblastoma patients and is impaired by tumor-derived TGF- $\beta$. Clin Cancer Res (2011) 17:4296-308. doi: 10.1158/1078-0432.CCR-10-2557 
96. Schmits R, Kündig TM, Baker DM, Shumaker G, Simard JJL, Duncan G, et al. LFA-1-deficient mice show normal CTL responses to virus but fail to reject immunogenic tumor. J Exp Med (1996) 183:1415-26. doi: 10.1084/jem.183.4.1415

97. Takeichi T, Mocevicius P, Deduchovas O, Salnikova O, Castro-Santa E, Büchler MW, et al. $\alpha 1 \beta 2$ integrin is indispensable for CD8 + T-cell recruitment in experimental pancreatic and hepatocellular cancer. Int $J$ Cancer (2012) 130:2067-76. doi: 10.1002/ijc.26223

98. Blank C, Brown I, Kacha AK, Markiewicz MA, Gajewski TF. ICAM-1 Contributes to but Is Not Essential for Tumor Antigen Cross-Priming and CD8 + T Cell-Mediated Tumor Rejection In Vivo. J Immunol (2005) 174:3416-20. doi: 10.4049/jimmunol.174.6.3416

99. Ley K, Laudanna C, Cybulsky MI, Nourshargh S. Getting to the site of inflammation: the leukocyte adhesion cascade updated. Nat Rev Immunol (2007) 7:678-89. doi: 10.1038/nri2156

100. Yu K D, Wang X, Yang C, Zeng XH, Shao ZM. Host genotype and tumor phenotype of chemokine decoy receptors integrally affect breast cancer relapse. Oncotarget (2015) 6:26519-27. doi: 10.18632/oncotarget.4470

101. Langenes V, Svensson H, Börjesson L, Gustavsson B, Bemark M, Sjöling Å, et al. Expression of the chemokine decoy receptor D6 is decreased in colon adenocarcinomas. Cancer Immunol Immunother (2013) 62:1687-95. doi: 10.1007/s00262-013-1472-0

102. Proost P, Schutyser E, Menten P, Struyf S, Wuyts A, Opdenakker G, et al. Amino-terminal truncation of CXCR3 agonists impairs receptor signaling and lymphocyte chemotaxis, while preserving antiangiogenic properties. Blood (2001) 98:3554-61. doi: 10.1182/blood.v98.13.3554

103. Sugita Y, Terasaki M, Nakashima S, Ohshima K, Morioka M, Abe H. The perivascular microenvironment in primary central nervous system lymphomas: the role of chemokines and the endothelin B receptor. Brain Tumor Pathol (2015) 32:41-8. doi: 10.1007/s10014-014-0206-0

104. Tanaka T, Sho M, Takayama T, Wakatsuki K, Matsumoto S, Migita K, et al. Endothelin $\mathrm{B}$ receptor expression correlates with tumour angiogenesis and prognosis in oesophageal squamous cell carcinoma. Br J Cancer (2014) 110:1027-33. doi: 10.1038/bjc.2013.784

105. Kodera M, Grailer JJ, Karalewitz APA, Subramanian H, Steeber DA. T lymphocyte migration to lymph nodes is maintained during homeostatic proliferation. Microsc Microanal (2008) 14:211-24. doi: 10.1017/ S1431927608080215

106. Abadier M, Pramod AB, McArdle S, Marki A, Fan Z, Gutierrez E, et al. Effector and Regulatory T Cells Roll at High Shear Stress by Inducible Tether and Sling Formation. Cell Rep (2017) 21:3885-99. doi: 10.1016/ j.celrep.2017.11.099

107. Yan M, Jene N, Byrne D, Millar EKA, O’Toole SA, McNeil CM, et al. Recruitment of regulatory T cells is correlated with hypoxia-induced CXCR4 expression, and is associated with poor prognosis in basal-like breast cancers. Breast Cancer Res (2011) 13(2):R47. doi: 10.1186/bcr2869

108. Karikoski M, Marttila-Ichihara F, Elima K, Rantakari P, Hollmén M, Kelkka T, et al. Clever- $1 /$ stabilin- 1 controls cancer growth and metastasis. Clin Cancer Res (2014) 20:6452-64. doi: 10.1158/1078-0432.CCR-14-1236

109. Malmberg KJ, Carlsten M, Björklund A, Sohlberg E, Bryceson YT, Ljunggren HG. Natural killer cell-mediated immunosurveillance of human cancer. Semin Immunol (2017) 31:20-9. doi: 10.1016/j.smim.2017.08.002

110. Chiossone L, Vienne M, Kerdiles YM, Vivier E. Natural killer cell immunotherapies against cancer: checkpoint inhibitors and more. Semin Immunol (2017) 31:55-63. doi: 10.1016/j.smim.2017.08.003

111. Ni L, Dong C. New checkpoints in cancer immunotherapy. Immunol Rev (2017) 276:52-65. doi: 10.1111/imr.12524

112. Guo X, Xue H, Shao Q, Wang J, Guo X, Chen X, et al. Hypoxia promotes glioma-associated macrophage infiltration via periostin and subsequent M2 polarization by upregulating TGF-beta and M-CSFR. Oncotarget (2016) 7:80521-42. doi: 10.18632/oncotarget.11825

113. Cai J, Xia L, Li J, Ni S, Song H, Wu X. Tumor-associated macrophages derived TGF- $\beta$-induced epithelial to mesenchymal transition in colorectal cancer cells through Smad2,3-4/Snail signaling pathway. Cancer Res Treat (2019) 51:252-6. doi: 10.4143/crt.2017.613

114. Liu Z, Kuang W, Zhou Q, Zhang Y. TGF- $\beta 1$ secreted by M2 phenotype macrophages enhances the stemness and migration of glioma cells via the SMAD2/3 signalling pathway. Int J Mol Med (2018) 42:3395-403. doi: $10.3892 /$ ijmm.2018.3923
115. Freud AG, Mundy-Bosse BL, Yu J, Caligiuri MA. The Broad Spectrum of Human Natural Killer Cell Diversity. Immunity (2017) 47:820-33. doi: 10.1016/j.immuni.2017.10.008

116. Sobolev O, Stern P, Lacy-Hulbert A, Hynes RO. Natural killer cells require selectins for suppression of subcutaneous tumors. Cancer Res (2009) 69:2531-9. doi: 10.1158/0008-5472.CAN-08-3126

117. Fogler WE, Volker K, McCormick KL, Watanabe M, Ortaldo JR, Wiltrout RH. NK cell infiltration into lung, liver, and subcutaneous B16 melanoma is mediated by VCAM-1/VLA-4 interaction. J Immunol (1996) 156:4707-14.

118. Castriconi R, Carrega P, Dondero A, Bellora F, Casu B, Regis S, et al. Molecular mechanisms directing migration and retention of natural killer cells in human tissues. Front Immunol (2018) 9:2324. doi: 10.3389/ fimmu.2018.02324

119. Gabrilovich DI, Nagaraj S. Myeloid-derived suppressor cells as regulators of the immune system. Nat Rev Immunol (2009) 9:162-74. doi: 10.1038/ nri2506

120. Coffelt SB, Wellenstein MD, De Visser KE. Neutrophils in cancer: Neutral no more. Nat Rev Cancer (2016) 16:431-46. doi: 10.1038/nrc.2016.52

121. Häuselmann I, Roblek M, Protsyuk D, Huck V, Knopfova L, Grässle S, et al. Monocyte induction of E-selectin-mediated endothelial activation releases VEcadherin junctions to promote tumor cell extravasation in the metastasis cascade. Cancer Res (2016) 76:5302-12. doi: 10.1158/0008-5472.CAN-16-0784

122. Läubli H, Stevenson JL, Varki A, Varki NM, Borsig L. L-selectin facilitation of metastasis involves temporal induction of Fut7-dependent ligands at sites of tumor cell arrest. Cancer Res (2006) 66:1536-42. doi: 10.1158/00085472.CAN-05-3121

123. Tazawa H, Okada F, Kobayashi T, Tada M, Mori Y, Une Y, et al. Infiltration of Neutrophils Is Required for Acquisition of Metastatic Phenotype of Benign Murine Fibrosarcoma Cells: Implication of InflammationAssociated Carcinogenesis and Tumor Progression. Am J Pathol (2003) 163:2221-32. doi: 10.1016/S0002-9440(10)63580-8

124. Ahn GO, Tseng D, Liao CH, Dorie MJ, Czechowicz A, Brown JM. Inhibition of Mac-1 (CD11b/CD18) enhances tumor response to radiation by reducing myeloid cell recruitment. Proc Natl Acad Sci USA (2010) 107:8363-8. doi: 10.1073/pnas.0911378107

125. Pelletier M, Maggi L, Micheletti A, Lazzeri E, Tamassia N, Costantini C, et al. Evidence for a cross-talk between human neutrophils and Th17 cells. Blood (2010) 115:335-43. doi: 10.1182/blood-2009-04-216085

126. Coffelt SB, Kersten K, Doornebal CW, Weiden J, Vrijland K, Hau C-S, et al. IL-17-producing $\gamma \delta \mathrm{T}$ cells and neutrophils conspire to promote breast cancer metastasis. Nature (2015) 522(7556):345-8. doi: 10.1038/nature14282

127. Bosteen MH, Tritsaris K, Hansen AJ, Dissing S. IL-17A potentiates TNF $\alpha$ induced secretion from human endothelial cells and alters barrier functions controlling neutrophils rights of passage. Pflugers Arch Eur J Physiol (2014) 466:961-72. doi: 10.1007/s00424-013-1354-5

128. Chao T, Furth EE, Vonderheide RH. CXCR2-dependent accumulation of tumor-associated neutrophils regulates T-cell immunity in pancreatic ductal adenocarcinoma. Cancer Immunol Res (2016) 4:968-82. doi: 10.1158/23266066.CIR-16-0188

129. Chen CL, Wang Y, Huang CY, Zhou ZQ, Zhao JJ, Zhang XF, et al. IL-17 induces antitumor immunity by promoting beneficial neutrophil recruitment and activation in esophageal squamous cell carcinoma. Oncoimmunology (2017) 7:1-11. doi: 10.1080/2162402X.2017.1373234

130. Blaisdell A, Crequer A, Colombus D, Daikoku T, Mittal K, Dey SK, et al. Neutrophils Oppose Uterine Epithelial Carcinogenesis via Debridement of Hypoxic Tumor Cells. Cancer Cell (2015) 28:785-99. doi: 10.1016/ j.ccell.2015.11.005.Neutrophils

131. Cavallo F, Di Carlo E, Butera M, Verrua R, Colombo MP, Musiani P, et al. Immune events associated with the cure of established tumors and spontaneous metastases by local and systemic interleukin 12. Cancer Res (1999) 59:414-21.

132. Juan TY, Roffler SR, Hou HS, Huang SM, Chen KC, Leu YL, et al. Antiangiogenesis targeting tumor microenvironment synergizes glucuronide prodrug antitumor activity. Clin Cancer Res (2009) 15:460011. doi: 10.1158/1078-0432.CCR-09-0090

133. Blaheta RA, Powerski M, Hudak L, Juengel E, Jonas D, von Knethen A, et al. Tumor-Endothelium Cross Talk Blocks Recruitment of Neutrophils to Endothelial Cells: A Novel Mechanism of Endothelial Cell Anergy. Neoplasia (2009) 11:1054-63. doi: 10.1593/neo.09762 
134. van Buul JD, van Rijssel J, van Alphen FPJ, van Stalborch A-M, Mul EPJ, Hordijk PL, et al. ICAM-1 clustering on endothelial cells recruits VCAM-1. J BioMed Biotechnol (2010) 2010:120328. doi: 10.1155/2010/120328

135. Jeong J, Suh Y, Jung K. Context Drives Diversification of Monocytes and Neutrophils in Orchestrating the Tumor Microenvironment. Front Immunol (2019) 10:1817. doi: 10.3389/fimmu.2019.01817

136. Qian BZ, Li J, Zhang H, Kitamura T, Zhang J, Campion LR, et al. CCL2 recruits inflammatory monocytes to facilitate breast-tumour metastasis. Nature (2011) 475:222-5. doi: 10.1038/nature10138

137. Chittezhath M, Dhillon MK, Lim JY, Laoui D, Shalova IN, Teo YL, et al. Molecular Profiling Reveals a Tumor-Promoting Phenotype of Monocytes and Macrophages in Human Cancer Progression. Immunity (2014) 41:81529. doi: 10.1016/j.immuni.2014.09.014

138. Chen Y, Huang Y, Reiberger T, Duyverman AM, Huang P, Samuel R, et al. Differential effects of sorafenib on liver versus tumor fibrosis mediated by stromal-derived factor 1 alpha/C-X-C receptor type 4 axis and myeloid differentiation antigen-positive myeloid cell infiltration in mice. Hepatology (2014) 59:1435-47. doi: 10.1002/hep.26790

139. Sanford DE, Belt BA, Panni RZ, Mayer A, Deshpande AD, Carpenter D, et al. Inflammatory monocyte mobilization decreases patient survival in pancreatic cancer: A role for targeting the CCL2/CCR2 axis. Clin Cancer Res (2013) 19:3404-15. doi: 10.1158/1078-0432.CCR-13-0525

140. Long KB, Gladney WL, Tooker GM, Graham K, Fraietta JA, Beatty GL. IFN $\gamma$ and CCL2 cooperate to redirect tumor-infiltrating monocytes to degrade fibrosis and enhance chemotherapy efficacy in pancreatic carcinoma. Cancer Discovery (2016) 6:400-13. doi: 10.1158/2159-8290.CD-15-1032

141. Porrello A, Leslie PL, Harrison EB, Gorentla BK, Kattula S, Ghosh SK, et al. Factor XIIIA-expressing inflammatory monocytes promote lung squamous cancer through fibrin cross-linking. Nat Commun (2018) 9(1):1988. doi: 10.1038/s41467-018-04355-w

142. Cortez-Retamozo V, Etzrodt M, Newton A, Ryan R, Pucci F, Sio SW, et al. Angiotensin II Drives the Production of Tumor-Promoting Macrophages. Immunity (2013) 38:296-308. doi: 10.1016/j.immuni.2012.10.015

143. Grossman JG, Nywening TM, Belt BA, Panni RZ, Krasnick BA, DeNardo DG, et al. Recruitment of CCR2 + tumor associated macrophage to sites of liver metastasis confers a poor prognosis in human colorectal cancer. Oncoimmunology (2018) 7:1-11. doi: 10.1080/2162402X.2018.1470729

144. Flores-Toro JA, Luo D, Gopinath A, Sarkisian MR, Campbell JJ, Charo IF, et al. CCR2 inhibition reduces tumor myeloid cells and unmasks a checkpoint inhibitor effect to slow progression of resistant murine gliomas. Proc Natl Acad Sci USA (2020) 117:1129-38. doi: 10.1073/pnas.1910856117

145. Borsig L, Wong R, Hynes RO, Varki NM, Varki A. Synergistic effects of Land $\mathrm{P}$-selectin in facilitating tumor metastasis can involve non-mucin ligands and implicate leukocytes as enhancers of metastasis. Proc Natl Acad Sci USA (2002) 99:2193-8. doi: 10.1073/pnas.261704098

146. Jin H, Su J, Garmy-Susini B, Kleeman J, Varner J. Integrin $\alpha 4 \beta 1$ promotes monocyte trafficking and angiogenesis in tumors. Cancer Res (2006) 66:2146-52. doi: 10.1158/0008-5472.CAN-05-2704

147. Czystowska-Kuzmicz M, Sosnowska A, Nowis D, Ramji K, Szajnik M, Chlebowska-Tuz J, et al. Small extracellular vesicles containing arginase-1 suppress T-cell responses and promote tumor growth in ovarian carcinoma. Nat Commun (2019) 10:1-16. doi: 10.1038/s41467-019-10979-3

148. Huang B, Lei Z, Zhao J, Gong W, Liu J, Chen Z, et al. CCL2/CCR2 pathway mediates recruitment of myeloid suppressor cells to cancers. Cancer Lett (2007) 252:86-92. doi: 10.1016/j.canlet.2006.12.012

149. Olingy CE, Dinh HQ, Hedrick CC. Monocyte heterogeneity and functions in cancer. J Leukoc Biol (2019) 106:309-22. doi: 10.1002/JLB.4RI0818-311R

150. Hanna RN, Cekic C, Sag D, Tacke R, Thomas GD, Nowyhed H, et al. Patrolling monocytes control tumor metastasis to the lung. Science (80- ) (2015) 350:985-90. doi: 10.1126/science.aac9407

151. Plebanek MP, Angeloni NL, Vinokour E, Li J, Henkin A, Martinez-Marin D, et al. Pre-metastatic cancer exosomes induce immune surveillance by patrolling monocytes at the metastatic niche. Nat Commun (2017) 8 (1):1319. doi: 10.1038/s41467-017-01433-3

152. Lavin Y, Kobayashi S, Leader A, Amir E ad D, Elefant N, Bigenwald C, et al. Innate Immune Landscape in Early Lung Adenocarcinoma by Paired SingleCell Analyses. Cell (2017) 169:750-765.e17. doi: 10.1016/j.cell.2017.04.014
153. Kubo H, Mensurado S, Gonçalves-Sousa N, Serre K, Silva-Santos B. Primary tumors limit metastasis formation through induction of IL15-mediated cross-talk between patrolling monocytes and NK cells. Cancer Immunol Res (2017) 5:812-20. doi: 10.1158/2326-6066.CIR-17-0082

154. Jung K, Heishi T, Khan OF, Kowalski PS, Incio J, Rahbari NN, et al. Ly6Clo monocytes drive immunosuppression and confer resistance to anti-VEGFR2 cancer therapy. J Clin Invest (2017) 127:3039-51. doi: 10.1172/JCI93182

155. Naxerova K, Reiter JG, Brachtel E, Lennerz JK, Van De Wetering M, Rowan A, et al. Origins of lymphatic and distant metastases in human colorectal cancer. Science (80- ) (2017) 357:55-60. doi: 10.1126/science.aai8515

156. Beerling E, Ritsma L, Vrisekoop N, Derksen PW, van Rheenen J. Intravital microscopy: new insights into metastasis of tumors. J Cell Sci (2011) 124:299-310. doi: $10.1242 /$ jcs. 072728

157. Siemann DW. The unique characteristics of tumor vasculature and preclinical evidence for its selective disruption by Tumor-Vascular Disrupting Agents. Cancer Treat Rev (2011) 37:63-74. doi: 10.1016/j.ctrv.2010.05.001

158. Hosaka K, Yang Y, Seki T, Fischer C, Dubey O, Fredlund E, et al. Pericytefibroblast transition promotes tumor growth and metastasis. Proc Natl Acad Sci USA (2016) 113:E5618-27. doi: 10.1073/pnas.1608384113

159. Nagy JA, Chang SH, Dvorak AM, Dvorak HF. Why are tumour blood vessels abnormal and why is it important to know? Br J Cancer (2009) 100:865-9. doi: 10.1038/sj.bjc.6604929

160. Abou Khouzam R, Goutham HV, Zaarour RF, Chamseddine AN, Francis A, Buart S, et al. Integrating tumor hypoxic stress in novel and more adaptable strategies for cancer immunotherapy. Semin Cancer Biol (2020) 65:140-54. doi: 10.1016/j.semcancer.2020.01.003

161. Zhang XD, Dong XQ, Xu JL, Chen SC, Sun Z. Hypoxia promotes epithelialmesenchymal transition of hepatocellular carcinoma cells via inducing Twistl expression. Eur Rev Med Pharmacol Sci (2017) 21:3061-8.

162. Schwab LP, Peacock DL, Majumdar D, Ingels JF, Jensen LC, Smith KD, et al. Hypoxia-inducible factor $1 \alpha$ promotes primary tumor growth and tumorinitiating cell activity in breast cancer. Breast Cancer Res (2012) 14:1-25. doi: $10.1186 /$ bcr3087

163. Schäffer L, Scheid A, Spielmann P, Breymann C, Zimmermann R, Meuli M, et al. Oxygen-regulated expression of TGF- $\beta 3$, a growth factor involved in trophoblast differentiation. Placenta (2003) 24:941-50. doi: 10.1016/S01434004(03)00166-8

164. Nishi H, Nakada T, Hokamura M, Osakabe Y, Itokazu O, Huang LE, et al. Hypoxia-inducible factor- 1 transactivates transforming growth factor- $\beta 3$ in trophoblast. Endocrinology (2004) 145:4113-8. doi: 10.1210/en.2003-1639

165. Chen J, Imanaka N, Chen J, Griffin JD. Hypoxia potentiates Notch signaling in breast cancer leading to decreased E-cadherin expression and increased cell migration and invasion. Br J Cancer (2010) 102:351-60. doi: 10.1038/ sj.bjc. 6605486

166. Stacker SA, Williams SP, Karnezis T, Shayan R, Fox SB, Achen MG. Lymphangiogenesis and lymphatic vessel remodelling in cancer. Nat Rev Cancer (2014) 14:159-72. doi: 10.1038/nrc3677

167. Stacker SA, Caesar C, Baldwin ME, Thornton GE, Williams RA, Prevo R, et al. VEGF-D promotes the metastatic spread of tumor cells via the lymphatics. Nat Med (2001) 7:186-91. doi: 10.1038/84635

168. Mandriota SJ, Jussila L, Jeltsch M, Compagni A, Baetens D, Prevo R, et al. Vascular endothelial growth factor-C-mediated lymphangiogenesis promotes tumour metastasis. EMBO J (2001) 20:672-82. doi: 10.1093/ emboj/20.4.672

169. Padera TP, Kadambi A, Di Tomaso E, Mouta Carreira C, Brown EB, Boucher Y, et al. Lymphatic metastasis in the absence of functional intratumor lymphatics. Science (80- ) (2002) 296:1883-6. doi: 10.1126/ science. 1071420

170. Pytowski B, Goldman J, Persaud K, Wu Y, Witte L, Hicklin DJ, et al. Complete and specific inhibition of adult lymphatic regeneration by a novel VEGFR-3 neutralizing antibody. J Natl Cancer Inst (2005) 97:14-21. doi: $10.1093 /$ jnci/dji003

171. Tvorogov D, Anisimov A, Zheng W, Leppänen VM, Tammela T, Laurinavicius S, et al. Effective Suppression of Vascular Network Formation by Combination of Antibodies Blocking VEGFR Ligand Binding and Receptor Dimerization. Cancer Cell (2010) 18:630-40. doi: $10.1016 /$ j.ccr.2010.11.001 
172. De Bock K, Cauwenberghs S, Carmeliet P. Vessel abnormalization: Another hallmark of cancer? Molecular mechanisms and therapeutic implications. Curr Opin Genet Dev (2011) 21:73-9. doi: 10.1016/j.gde.2010.10.008

173. Carmeliet P, Jain RK. Principles and mechanisms of vessel normalization for cancer and other angiogenic diseases. Nat Rev Drug Discovery (2011) 10:41727. doi: $10.1038 / \mathrm{nrd} 3455$

174. Levin VA, Mendelssohn ND, Chan J, Stovall MC, Peak SJ, Yee JL, et al. Impact of bevacizumab administered dose on overall survival of patients with progressive glioblastoma. J Neurooncol (2015) 122:145-50. doi: 10.1007/ s11060-014-1693-x

175. Jayson GC, Kerbel R, Ellis LM, Harris AL. Antiangiogenic therapy in oncology: current status and future directions. Lancet (2016) 388:518-29. doi: 10.1016/S0140-6736(15)01088-0

176. Jain RK, Duda DG, Clark JW, Loeffler JS. Lessons from phase III clinical trials on anti-VEGF therapy for cancer. Nat Clin Pract Oncol (2006) 3:24-40. doi: $10.1038 /$ ncponc0403

177. Chae SS, Kamoun WS, Farrar CT, Kirkpatrick ND, Niemeyer E, De Graaf AMA, et al. Angiopoietin-2 interferes with anti-VEGFR2-induced vessel normalization and survival benefit in mice bearing gliomas. Clin Cancer Res (2010) 16:3618-27. doi: 10.1158/1078-0432.CCR-09-3073

178. Kim HS, Won YJ, Shim JH, Kim HJ, Kim J, Hong HN, et al. Morphological characteristics of vasculogenic mimicry and its correlation with EphA2 expression in gastric adenocarcinoma. Sci Rep (2019) 9:1-13. doi: 10.1038/ s41598-019-40265-7

179. Allen E, Jabouille A, Rivera LB, Lodewijckx I, Missiaen R, Steri V, et al. Combined antiangiogenic and anti-PD-L1 therapy stimulates tumor immunity through HEV formation. Sci Transl Med (2017) 9(385): eak9679. doi: 10.1126/scitranslmed.aak9679

180. Greenberg JI, Shields D, Barillas SG, Acevedo LM, Murphy E, Huang J, et al. A Role for VEGF as a Negative Regulator of Pericyte Function and Vessel Maturation. Nature (2008) 456:809-13. doi: 10.1038/nature07424

181. Hansen-Algenstaedt N, Stoll BR, Padera TP, Dolmans DEJGJ, Hicklin DJ, Fukumura D, et al. Tumor oxygenation in hormone-dependent tumors during vascular endothelial growth factor receptor-2 blockade, hormone ablation, and chemotherapy. Cancer Res (2000) 60:4556-60.

182. Dings RPM, Loren M, Heun H, Mcniel E, Griffioen AW, Mayo KH, et al. Scheduling of Radiation with Angiogenesis Inhibitors Anginex and Avastin Improves Therapeutic Outcome via Vessel Normalization. Clin Cancer Res (2007) 13:3395-403. doi: 10.1158/1078-0432.CCR-06-2441

183. Mcgee MC, Hamner JB, Williams RF, Rosati F, Sims TL, Ng CY, et al. Improved intratumoral oxygenation through vascular normalization increases glioma sensitivity to ionizing radiation. Int J Radiat Oncol (2010) 76:1537-45. doi: 10.1016/j.ijrobp.2009.12.010.Improved

184. Winkler F, Kozin SV, Tong RT, Chae S-S, Booth MF, Garkavtsev I, et al. Kinetics of vascular normalization by VEGFR2 blockade governs brain tumor response to radiation. Cancer Cell (2004) 6:553-63. doi: 10.1016/j.ccr.2004.10.011

185. Tong RT, Boucher Y, Kozin SV, Winkler F, Hicklin DJ, Jain RK. Vascular normalization by vascular endothelial growth factor receptor 2 blockade induces a pressure gradient across the vasculature and improves drug penetration in tumors. Cancer Res (2004) 64:3731-6. doi: 10.1158/00085472.CAN-04-0074

186. Inai $\mathrm{T}$, Mancuso $\mathrm{M}$, Hashizume $\mathrm{H}$, Baffert $\mathrm{F}$, Haskell A, Baluk $\mathrm{P}$, et al. Inhibition of Vascular Endothelial Growth Factor (VEGF) Signaling in Cancer Causes Loss of Endothelial Fenestrations, Regression of Tumor Vessels, and Appearance of Basement Membrane Ghosts. Am J Pathol (2004) 165:35-52. doi: 10.1016/S0002-9440(10)63273-7

187. Li B, Lalani AS, Harding TC, Luan B, Koprivnikar K, Huantu G, et al. Vascular Endothelial Growth Factor Blockade Reduces Intratumoral Regulatory T Cells and Enhances the Efficacy of a GM-CSF ^ Secreting Cancer Immunotherapy. Clin Cancer Res (2006) 12:6808-17. doi: 10.1158/1078-0432.CCR-06-1558

188. Kwilas AR, Ardiani A, Donahue RN, Aftab DT, Hodge JW. Dual effects of a targeted small-molecule inhibitor (cabozantinib) on immune-mediated killing of tumor cells and immune tumor microenvironment permissiveness when combined with a cancer vaccine. J Transl Med (2014) 12:1-15. doi: 10.1186/s12967-014-0294-y

189. Tian L, Goldstein A, Wang H, Lo HC, Kim IS, Welte T, et al. Mutual regulation of tumour vessel normalization and immunostimulatory reprogramming. Nature (2017) 544:250-4. doi: 10.1038/nature21724
190. Schmittnaegel M, Rigamonti N, Kadioglu E, Cassará A, Rmili CW, Kiialainen A, et al. Dual angiopoietin-2 and VEGFA inhibition elicits antitumor immunity that is enhanced by PD-1 checkpoint blockade. Sci Transl Med (2017) 9(385): eaak9670. doi: 10.1126/scitranslmed.aak9670

191. Schoenfeld J, Jinushi M, Nakazaki Y, Wiener D, Park J, Soiffer R, et al. Active immunotherapy induces antibody responses that target tumor angiogenesis. Cancer Res (2010) 70:10150-60. doi: 10.1158/0008-5472.CAN-10-1852

192. Renner DN, Malo CS, Jin F, Parney IF, Pavelko KD, Johnson AJ. Improved Treatment Efficacy of Antiangiogenic Therapy when Combined with Picornavirus Vaccination in the GL261 Glioma Model. Neurotherapeutics (2016) 13(1):226-36. doi: 10.1007/s13311-015-0407-1

193. Tao L, Huang G, Shi S, Chen L. Bevacizumab improves the antitumor efficacy of adoptive cytokine-induced killer cells therapy in non-small cell lung cancer models. Med Oncol (2014) 31(1):777. doi: 10.1007/s12032-013-0777-3

194. Wang W, Ma Y, Li J, Shi HS, Wang LQ, Guo FC, et al. Specificity redirection by CAR with human VEGFR-1 affinity endows T lymphocytes with tumorkilling ability and anti-angiogenic potency. Gene Ther (2013) 20:970-8. doi: $10.1038 /$ gt.2013.19

195. Yasuda S, Sho M, Yamato I. Simultaneous blockade of programmed death 1 and vascular endothelial growth factor receptor 2 (VEGFR2) induces synergistic anti-tumour effect in vivo. Clin Exp Immunol (2013) 172 (31):500-6. doi: $10.1111 /$ cei.12069

196. Wu FTH, Man S, Xu P, Chow A, Paez-Ribes M, Lee CR, et al. Efficacy of cotargeting angiopoietin-2 and the VEGF pathway in the adjuvant postsurgical setting for early breast, colorectal, and renal cancers. Cancer Res (2016) 76:6988-7000. doi: 10.1158/0008-5472.CAN-16-0888

197. Avella DM, Li G, Schell TD, Liu D, Zhang SS, Lou X, et al. Regression of Established Hepatocellular Carcinoma Is Induced by Chemoimmunotherapy in an Orthotopic Murine Model. Hepatology (2012) 55:141-52. doi: 10.1002/ hep. 24652

198. Farsaci B, Higgins JP, Hodge JW. Consequence of dose scheduling of sunitinib on host immune response elements and vaccine combination therapy. In J Cancer (2012) 130(8):1948-59. doi: 10.1002/ijc.26219

199. Du Four S, Maenhout SK, Niclou SP, Thielemans K, Neyns B, Aerts JL. Combined VEGFR and CTLA-4 blockade increases the antigen-presenting function of intratumoral DCs and reduces the suppressive capacity of intratumoral MDSCs. Am J Cancer Res (2016) 6:2514-31.

200. Meder L, Schuldt P, Thelen M, Schmitt A, Dietlein F, Klein S, et al. Combined VEGF and PD-L1 blockade displays synergistic treatment effects in an autochthonous mouse model of small cell lung cancer. Cancer Res (2018) 78:4270-81. doi: 10.1158/0008-5472.CAN-17-2176

201. Wu X, Giobbie-hurder A, Liao X, Connelly C, Erin M, Li J, et al. Angiopoietin-2 as a biomarker and target for immune checkpoint therapy. Cancer Immunol Res (2017) 5:17-28. doi: 10.1158/2326-6066.CIR-16-0206.Angiopoietin-2

202. Shigeta K, Datta M, Hato T, Kitahara S, Chen IX, Matsui A, et al. Dual Programmed Death Receptor-1 and Vascular Endothelial Growth Factor Receptor-2 Blockade Promotes Vascular Normalization and Enhances Antitumor Immune Responses in Hepatocellular Carcinoma. Hepatology (2020) 71:1247-61. doi: 10.1002/hep.30889

203. Shi S, Wang R, Chen Y, Song H, Chen L, Huang G. Combining Antiangiogenic Therapy with Adoptive Cell Immunotherapy Exerts Better Antitumor Effects in Non-Small Cell Lung Cancer Models. PloS One (2013) 8(6):e65757. doi: 10.1371/journal.pone.0065757

204. Dickson PV, Hamner JB, Sims TL, Fraga CH, Ng CYC, Rajasekeran S, et al. Bevacizumab-induced transient remodeling of the vasculature in neuroblastoma xenografts results in improved delivery and efficacy of systemically administered chemotherapy. Clin Cancer Res (2007) 13:394250. doi: 10.1158/1078-0432.CCR-07-0278

205. Koh YJ, Kim HZ, Hwang SI, Lee JE, Oh N, Jung K, et al. Double antiangiogenic protein, DAAP, targeting VEGF-A and angiopoietins in tumor angiogenesis, metastasis, and vascular leakage. Cancer Cell (2010) 18:171-84. doi: 10.1016/j.ccr.2010.07.001

206. Peterson TE, Kirkpatrick ND, Huang Y, Farrar CT, Marijt KA. Dual inhibition of Ang-2 and VEGF receptors normalizes tumor vasculature and prolongs survival in glioblastoma by altering macrophages. Proc Natl Acad Sci USA (2016) 113:4470-5. doi: 10.1073/pnas.1525349113

207. Rini BI, Halabi S, Rosenberg JE, Stadler WM, Vaena DA, Archer L, et al. Phase III trial of bevacizumab plus interferon alfa versus interferon alfa monotherapy in 
patients with metastatic renal cell carcinoma: Final results of CALGB 90206. J Clin Oncol (2010) 28:2137-43. doi: 10.1200/JCO.2009.26.5561

208. Escudier B, Bellmunt J, Négrier S, Bajetta E, Melichar B, Bracarda S, et al. Phase III trial of bevacizumab plus interferon alfa-2a in patients with metastatic renal cell carcinoma (AVOREN): Final analysis of overall survival. J Clin Oncol (2010) 28:2144-50. doi: 10.1200/JCO.2009.26.7849

209. Amin A, Dudek AZ, Logan TF, Lance RS, Holzbeierlein JM, Knox JJ, et al. Survival with AGS-003, an autologous dendritic cell-based immunotherapy, in combination with sunitinib in unfavorable risk patients with advanced renal cell carcinoma (RCC): Phase 2 study results. J Immunother Cancer (2015) 3:1-13. doi: 10.1186/s40425-015-0055-3

210. Hodi FS, Lawrence D, Lezcano C, Wu X, Zhou J, Sasada T, et al. Bevacizumab plus Ipilimumab in Patients with Metastatic Melanoma. Cancer Immunol Res (2014) 2:632-42. doi: 10.1038/jid.2014.371

211. Amin A, Plimack ER, Ernstoff MS, Lewis LD, Bauer TM, McDermott DF, et al. Safety and efficacy of nivolumab in combination with sunitinib or pazopanib in advanced or metastatic renal cell carcinoma: The CheckMate 016 study. J Immunother Cancer (2018) 6:1-12. doi: 10.1186/s40425-018-0420-0

212. Arkenau H, Martin-Liberal J, Calvo E, Penel N, Krebs MG, Herbst RS, et al. Ramucirumab Plus Pembrolizumab in Patients with Previously Treated Advanced or Metastatic Biliary Tract Cancer: Nonrandomized, OpenLabel, Phase I Trial (JVDF). Oncologist (2018) 23:1407. doi: 10.1634/ theoncologist.2018-0044

213. McGregor BA, McKay RR, Braun DA, Werner L, Gray K, Flaifel A, et al. Results of a multicenter phase II study of atezolizumab and bevacizumab for patients with metastatic renal cell carcinoma with variant histology and/or sarcomatoid features. J Clin Oncol (2020) 38:63-70. doi: 10.1200/JCO.19.01882

214. Liu SV, Camidge DR, Gettinger SN, Giaccone G, Heist RS, Hodi FS, et al. Long-term survival follow-up of atezolizumab in combination with platinum-based doublet chemotherapy in patients with advanced nonsmall-cell lung cancer. Eur J Cancer (2018) 101:114-22. doi: 10.1016/ j.ejca.2018.06.033

215. Reck M, Mok TSK, Nishio M, Jotte RM, Cappuzzo F, Orlandi F, et al. Atezolizumab plus bevacizumab and chemotherapy in non-small-cell lung cancer (IMpower150): key subgroup analyses of patients with EGFR mutations or baseline liver metastases in a randomised, open-label phase 3 trial. Lancet Respir Med (2019) 7:387-401. doi: 10.1016/S2213-2600(19)30084-0

216. Socinski MA, Jotte RM, Cappuzzo F, Orlandi F, Stroyakovskiy D, Nogami N, et al. Atezolizumab for first-line treatment of metastatic nonsquamous NSCLC. N Engl J Med (2018) 378:2288-301. doi: 10.1056/NEJMoa1716948

217. Choueiri TK, Larkin J, Oya M, Thistlethwaite F, Martignoni M, Nathan P, et al. Preliminary results for avelumab plus axitinib as first-line therapy in patients with advanced clear-cell renal-cell carcinoma (JAVELIN Renal 100): an open-label, dose-finding and dose-expansion, phase $1 \mathrm{~b}$ trial. Lancet Oncol (2018) 19:451-60. doi: 10.1016/S1470-2045(18)30107-4

218. Choueiri TK, Motzer RJ, Rini BI, Haanen J, Campbell MT, Venugopal B, et al. Updated efficacy results from the JAVELIN Renal 101 trial: first-line avelumab plus axitinib versus sunitinib in patients with advanced renal cell carcinoma. Ann Oncol (2020) 31(8):1030-39. doi: 10.1016/j.annonc.2020.04.010

219. Motzer RJ. Avelumab plus Axitinib versus Sunitinib for Advanced RenalCell Carcinoma. Physiol Behav (2018) 176:139-48. doi: 10.1016/ j.physbeh.2017.03.040

220. Xu J, Zhang Y, Jia R, Yue C, Chang L, Liu R, et al. Anti-PD-1 antibody SHR1210 combined with apatinib for advanced hepatocellular carcinoma, gastric, or esophagogastric junction cancer: An Open-label, Dose Escalation and Expansion Study. Clin Cancer Res (2019) 25:515-23. doi: 10.1158/10780432.CCR-18-2484

221. Huo M, Zhao Y, Satterlee AB, Wang Y, Xu Y, Huang L. Tumor-targeted delivery of sunitinib base enhances vaccine therapy for advanced melanoma by remodeling the tumor microenvironment. J Control Release (2017) 245:81-94. doi: 10.1016/j.physbeh.2017.03.040

222. Rini BI, Plimack ER, Stus V, Gafanov R, Hawkins R, Nosov D, et al. Pembrolizumab plus axitinib versus sunitinib for advanced renal-cell carcinoma. N Engl J Med (2019) 380:1116-27. doi: 10.1056/NEJMoa1816714

223. Kandalaft LE, Powell DJ, Chiang CL, Tanyi J, Kim S, Bosch M, et al. Autologous lysate-pulsed dendritic cell vaccination followed by adoptive transfer of vaccine-primed ex vivo co-stimulated t cells in recurrent ovarian cancer. Oncoimmunology (2013) 2:37-41. doi: 10.4161/onci.22664
224. De Bock K, Georgiadou M, Schoors S, Kuchnio A, Wong BW, Cantelmo AR, et al. Role of PFKFB3-driven glycolysis in vessel sprouting. Cell (2013) 154:651-63. doi: 10.1016/j.cell.2013.06.037

225. Schoors S, De Bock K, Cantelmo AR, Georgiadou M, Ghesquière B, Cauwenberghs $S$, et al. Partial and transient reduction of glycolysis by PFKFB3 blockade reduces pathological angiogenesis. Cell Metab (2014) 19:37-48. doi: 10.1016/j.cmet.2013.11.008

226. Cantelmo AR, Conradi LC, Brajic A, Goveia J, Kalucka J, Pircher A, et al. Inhibition of the Glycolytic Activator PFKFB3 in Endothelium Induces Tumor Vessel Normalization, Impairs Metastasis, and Improves Chemotherapy. Cancer Cell (2016) 30:968-85. doi: 10.1016/ j.ccell.2016.10.006

227. Conradi LC, Brajic A, Cantelmo AR, Bouché A, Kalucka J, Pircher A, et al. Tumor vessel disintegration by maximum tolerable PFKFB3 blockade. Angiogenesis (2017) 20:599-613. doi: 10.1007/s10456-017-9573-6

228. Rohlenova K, Goveia J, García-Caballero M, Subramanian A, Kalucka J, Treps L, et al. Single-Cell RNA Sequencing Maps Endothelial Metabolic Plasticity in Pathological Angiogenesis. Cell Metab (2020) 31:862-877.e14. doi: 10.1016/j.cmet.2020.03.009

229. Johansson A, Hamzah J, Payne CJ, Ganss R. Tumor-targeted TNF $\alpha$ stabilizes tumor vessels and enhances active immunotherapy. Proc Natl Acad Sci U.S.A. (2012) 109:7841-6. doi: 10.1073/pnas.1118296109

230. Calcinotto A, Grioni M, Jachetti E, Curnis F, Mondino A, Parmiani G, et al. Targeting TNF- $\alpha$ to Neoangiogenic Vessels Enhances Lymphocyte Infiltration in Tumors and Increases the Therapeutic Potential of Immunotherapy. J Immunol (2012) 188:2687-94. doi: 10.4049/ jimmunol.1101877

231. Rybak JN, Roesli C, Kaspar M, Villa A, Neri D. The extra-domain A of fibronectin is a vascular marker of solid tumors and metastases. Cancer Res (2007) 67:10948-57. doi: 10.1158/0008-5472.CAN-07-1436

232. Neri D, Carnemolla B, Nissim A, Leprini A, Querzè G, Balza E, et al. Targeting by affinity-matured recombinant antibody fragments of an angiogenesis associated fibronectin isoform. Nat Biotechnol (1997) 15:1271-5. doi: 10.1038/nbt1197-1271

233. Santimaria M, Moscatelli G, Viale GL, Giovannoni L, Neri G, Viti F, et al. Immunoscintigraphic detection of the ED-B domain of fibronectin, a marker of angiogenesis, in patients with cancer. Clin Cancer Res (2003) 9:571-9.

234. Johannsen M, Spitaleri G, Curigliano G, Roigas J, Weikert S, Kempkensteffen C, et al. The tumour-targeting human L19-IL2 immunocytokine: Preclinical safety studies, phase i clinical trial in patients with solid tumours and expansion into patients with advanced renal cell carcinoma. Eur J Cancer (2010) 46:2926-35. doi: 10.1016/j.ejca.2010.07.033

235. Carnemolla B, Borsi L, Balza E, Castellani P, Meazza R, Berndt A, et al. Enhancement of the antitumor properties of interleukin-2 by its targeted delivery to the tumor blood vessel extracellular matrix. Blood (2002) 99:1659-65. doi: 10.1182/blood.V99.5.1659

236. Danielli R, Patuzzo R, Maria A, Giacomo D, Gallino G, Maurichi A, et al. Intralesional administration of L19 - IL2 / L19 - TNF in stage III or stage IVM1a melanoma patients : results of a phase II study. Cancer Immunol Immunother (2015) 65:999-1009. doi: 10.1007/s00262-015-1704-6

237. Palazón A, Teijeira A, Martínez-Forero I, Hervás-Stubbs S, Roncal C, Peñuelas I, et al. Agonist anti-CD137 mAb act on tumor endothelial cells to enhance recruitment of activated T lymphocytes. Cancer Res (2011) 71:801-11. doi: 10.1158/0008-5472.CAN-10-1733

238. Li S, Jiang Q, Liu S, Zhang Y, Tian Y, Song C, et al. A DNA nanorobot functions as a cancer therapeutic in response to a molecular trigger in vivo. Nat Biotechnol (2018) 36:258-64. doi: 10.1038/nbt.4071

Conflict of Interest: The authors declare that the research was conducted in the absence of any commercial or financial relationships that could be construed as a potential conflict of interest.

Copyright $\odot 2020$ Duru, van Egmond and Heemskerk. This is an open-access article distributed under the terms of the Creative Commons Attribution License (CC BY). The use, distribution or reproduction in other forums is permitted, provided the original author(s) and the copyright owner(s) are credited and that the original publication in this journal is cited, in accordance with accepted academic practice. No use, distribution or reproduction is permitted which does not comply with these terms. 